\title{
JUMPSTARTING THE SOCIALIZATION EXPERIENCE: THE LONGITUDINAL ROLE OF DAY ONE NEWCOMER RESOURCES ON ADJUSTMENT
}

\author{
Talya N. Bauer \\ Portland State University \\ Berrin Erdogan \\ Portland State University \\ University of Exeter \\ David Caughlin \\ Portland State University \\ Allison Ellis \\ Cal Poly, San Luis Obispo \\ Jennifer Kurkoski \\ Google LLC
}

Acknowledgements: The authors thank Tim Oxendahl for his help with this manuscript. We also thank the Associate Editor and two anonymous reviewers for their helpful comments on earlier versions of this manuscript throughout the review process.

Keywords: Socialization/Orienting New Employees; Careers; Selection/Staffing; Training and Development; Growth/Longitudinal Modeling 


\title{
JUMPSTARTING THE SOCIALIZATION EXPERIENCE：THE LONGITUDINAL ROLE OF DAY ONE NEWCOMER RESOURCES ON ADJUSTMENT
}

\begin{abstract}
We examine the newcomer adjustment patterns of 985 new hires at a Fortune 500 technology organization across their first year on the job. Data were collected from newcomers, their managers, and company records from organizational entry (employee's first day) to the end of the first year of employment. First, we examined whether newcomer resources (material, personal, social, and status resources) related to early newcomer adjustment levels (role clarity, task mastery, and acceptance) and rates of adjustment. Second, how newcomer resources and the rate of adjustment related to manager-ratings of newcomer adjustment at 9 and 12 months post-entry. The average of every adjustment variable was higher at the latest data collection point indicating that time was on newcomers' side and was related, overall, to higher adjustment levels. Finally, we explored which resources related to the three newcomer adjustment indicators and the shapes adjustment trajectories took depending on resources at organizational entry. Results indicated that personal resources (proactive personality, optimism, and organizational knowledge) were related to early adjustment. Regarding material resources, having a work station ready their first day on the job was related to adjustment. For social resources, meeting one's manager the first day on the job was related to early social acceptance. For status resources, greater newcomer job level was unexpectedly not related to early adjustment. Partial support was found for the direct relationships between early adjustment levels or adjustment rates and manager ratings of adjustment at 9 months, but limited support for manager ratings of adjustment at 12 months.
\end{abstract}

Keywords: organizational socialization; new employee adjustment; conservation of resources 


\section{JUMPSTARTING THE SOCIALIZATION EXPERIENCE：THE LONGITUDINAL ROLE OF DAY ONE NEWCOMER RESOURCES ON ADJUSTMENT}

Most individuals experience multiple work role transitions, moving from one role to another, throughout their lives (Ashforth, 2001), with adults changing jobs 12.3 times during their lifetime (U.S. Bureau of Labor Statistics, 2019). For new employees, these transitions are salient experiences where the stakes are high. Newcomers must 'learn the ropes', both in terms of performing their new job as well as fitting in with new colleagues. They explore their environment while weighing their expectations against reality, garnering an understanding of their fit with their new environment, and impacting and changing that environment. This process of moving from organizational outsider to organizational insider is termed organizational socialization and its importance has not been lost on scholars or organizations. Scholars have made great strides in understanding this process since the 1970s when it was first introduced in the literature (see Wanberg, 2012). It is established that organizational practices and newcomer behaviors early in a new employee's tenure play significant roles in the adjustment of those newcomers (Allen, Eby, Chao, \& Bauer, 2017), and meta-analytic evidence suggests that newcomer adjustment assessed early in the socialization process is related to important distal outcomes such as performance, job satisfaction, and turnover (Bauer, Bodner, Erdogan, Truxillo, \& Tucker, 2007; Saks, Uggerslev, \& Fassina, 2007) also underscoring the practical relevance of this process.

Although the organizational socialization literature has acknowledged the reciprocal influence of both newcomer and organization on one another (Li, Harris, Boswell, \& Xie, 2011; Reichers, 1987), it has been less common to examine the process through the lens of the newcomers themselves with a focus on the demanding and sometimes stressful nature of the transition. In their review of the literature, Ellis et al. (2015) argued that a newcomer-centric view of socialization necessitates the inclusion of how newcomers appraise and cope with the uncertainty and stress of 
starting a new job. Drawing upon Conservation of Resources (COR) theory, they argued that such a perspective highlights how newcomer adjustment processes are set into motion and where they might derail. Central to this line of reasoning is the role of newcomer resources which includes anything perceived by newcomers as helping them achieve their goals (Halbesleben, Neveu, Paustian-Underdahl, \& Westman, 2014). COR theory proposes that each individual carries a unique reservoir of acquired resources which they have at their disposal during times of stress (Hobfoll, 1989, 2010). Some research suggests that specific personality traits and experiences can help newcomers cope with demands, and may therefore serve as newcomer resources (Ashforth, Sluss, \& Saks, 2007; Saks \& Ashforth, 2000). But, as Ellis et al. (2015) and Saks and Gruman (2012) note, the examination of how these potential newcomer resources influence the adjustment process has been piecemeal, leading to an unclear picture of whether, and what types of, newcomer resources matter for initiating successful newcomer adjustment and an incomplete understanding of the newcomer socialization process from the newcomer's point of view.

At a fundamental level, there has been little attention paid to the possibility that, due to their differential access to resources, newcomers may show different rates of adjustment, and demonstrate different patterns of adjustment over time. Although scholars have examined cross-sectional antecedents of adjustment (Reio \& Callahan, 2004), cross-lagged measures of adjustment (e.g., Kammeyer-Mueller \& Wanberg, 2003), and consequences of adjustment (Allen \& Shanock, 2013; Lapointe, Vandenberghe, \& Boundrias, 2014), few scholars have tackled the important question of whether resources matter for adjustment and adjustment rates, how newcomer adjustment patterns evolve, or what form rates of newcomers adjustment might take in response to certain resources. Integration of COR theory and the concept of newcomer resources provides a framework for investigating these changes. 
In this study, we set out to examine two distinct, but related, aspects of newcomer adjustment. First, we set out to test the general relationship between resources and adjustment, including whether resources at entry predict newcomer perceptions of adjustment early on, which also sets them up to be more successful over the course of their first year. We propose that this matters not just for how newcomers feel, but should translate into tangible ratings by managers. Thus, we are interested in how resources jumpstart the newcomer socialization process and how this relates to adjustment (as perceived by newcomers and others) over the first year. Second, we explored specific resources and specific aspects of adjustment to examine overall relationships and, further, to explore which resources matter most for early levels and rates of different indicators of adjustment. To address these two goals, we studied a group of incoming newcomers at a Fortune 500 technology organization. We followed them from their first day on the job via data provided by archival company records and newcomer surveys on their first day, longitudinal newcomer surveys at 1 month, 3 months, 6 months, and 9 months post-entry. In addition, adjustment ratings were gathered from managers at 9 and 12 months post-entry. Our longitudinal research design for newcomer data afforded us the ability to relate newcomer resources to adjustment in general and to explore specific levels and patterns of adjustment over time as the newcomers transform from organizational outsiders to organizational insiders.

To this end, our study seeks to make three specific contributions to the literature in three distinct phases of analysis. First, our study extends Hobfoll's (1988) argument that understanding individuals' access to resources is helpful to understanding their coping and adjustment when faced with challenging circumstances such as starting a new job (Ashforth, 2001). Second, to our knowledge, this is the first study to examine resources in relation to adjustment patterns across the first year on the job to delineate how resources relate to differential patterns of change in adjustment (Hobfoll, 1988, 2001). Finally, third, in line with Ellis et al. who urged researchers to focus on "articulating the 
resources that matter to socialization, [and] understanding how and why they matter" (2015: 226), the current study examines a set of theory-based resources following Hobfoll's (2002) typology of material, personal, social, and status resources in relation to specific indicators of adjustment over time. To our knowledge, no study has focused on the influence of such a constellation of specific resources initially available to newcomers in the context of newcomer adjustment and as adjustment trajectories are set into motion. By examining the role of specific resources on early newcomer adjustment, we add to our existing knowledge of both socialization and COR theory in the context of new employee adjustment. We further identify if greater resources early on give individuals a natural advantage as they begin the process of adjustment, as well as whether certain resources matter more than others. Taken together, we address a clear gap in our current understanding of the nature of early newcomer adjustment levels and how differential adjustment rates over time affect ultimate socialization success.

\section{Conservation of Resource (COR) Theory and Organizational Socialization}

Conservation of Resources (COR) theory is a dynamic model which focuses on how individuals approach challenging situations in terms of resources and resilience (Hobfoll, 1989). Central to the theory is the concept of resources. Halbesleben et al. (2014) defined resources as things which might help an individual attain their goals. A foundational principle of COR is that individuals are motivated by their desire to acquire and retain resources rather than having them depleted without replenishment. That is because resources have instrumental value in terms of facilitating individuals' ability to meet their goals and effectively cope with demands they face at work (Halbesleben et al., 2014), as well as symbolic value in that they reinforce identity and positive perceptions of the self (Hobfoll, 1989). The availability of resources also makes the acquisition of future resources more likely. Hobfoll proposed that individuals with access to resources are better poised to gain additional resources, while those with fewer resources are set up to lose resources. 
Applying the logic of COR theory to the adjustment process, Ellis et al. argued that socialization is a period when "newcomers take inventory of resources available to them and use this information to determine the extent to which they have the available resources to meet the demand" (2015: 207). When starting a new job, the availability of resources is made especially salient to new employees and can jumpstart adjustment during the socialization process. Thus, those with access to greater levels of resources on the first day of the job, which is the onset of the socialization process, are poised to deal with the early challenges of organizational socialization. Individuals who have access to resources that fit the demands of the situation will be better positioned to deal with adversity and stressful circumstances (Hobfoll, 2002). In turn, these newcomers should exhibit better adjustment to their new working context.

In the organizational socialization literature, newcomer adjustment is often characterized by three indicators: role clarity, task mastery, and feelings of acceptance (Allen et al., 2017; Bauer et al., 2007; Wanberg, 2012). Role clarity is defined as understanding what to do, how to do it, and how to prioritize tasks (Feldman \& March, 1981). Task mastery is defined as gaining confidence in one's new role (Bauer et al., 2007). Feelings of acceptance refer to feeling liked and trusted by one's colleagues (Bauer \& Green, 1998). All three constructs have been identified as indicating newcomer adjustment and these adjustment indicators then relate to later newcomer outcomes such as job attitudes and performance (Wanberg, 2012).

\section{Model Overview and Hypothesis Development}

\section{Newcomer Resources on Early Levels of Adjustment and Rate of Adjustment}

Hobfoll (2002) identified four categories of relevant resources which can be understood in the context of work: material resources such as tools and equipment for work; personal resources such as one's personality traits, knowledge, and skills; social resources which include social support and the network available to an individual; and status resources which increase a person's power, 
such as seniority and leadership. As illustrated in Figure 1, based on COR theory, we identified resources which were available to newcomers for each type of resource. We considered two material resources: having one's work station and computer ready for the first day on the job. For personal resources, we focused on a well-established personality factor, newcomer proactive personality (e.g., Li et al., 2011), as well as newcomer optimism which has rarely been included in studies of socialization but has been considered a personal job resource by COR researchers (Bakker, Tims, $\&$ Derks, 2012; Xanthopoulou, Bakker, Demerouti, \& Schaufeli, 2009). We also examined prior knowledge of the organization and work experience as personal resources. We considered two social resources: whether the employee met with their manager on the first day, and insider relationships, indicated by whether the individual had friends and family members working in the organization. Finally, we identified job level as the status resource available to newcomers on their first day.

At a general level, we argue that those with greater resources will adjust more readily early on compared to those who enter the organization with fewer resources. Specifically, those newcomers with an abundance of resources will be better poised to meet demands such as coping with ambiguity and will feel more efficacious in their ability to perform their job and become a valued member of the organization. That is, the availability of resources should be associated with a better starting point in terms of early adjustment. As a result, employees who are in possession of greater levels of resources on their first day on the job are more likely to report early higher levels of adjustment as indicated by greater role clarity, task mastery, and acceptance compared to others who have lower levels of resources at the onset.

COR theory also has the potential to help us understand how newcomer differences in resources upon organizational entry may influence adjustment over time. An important tenet of COR theory is that individuals are motivated to protect, maintain, and build resources - which of these behaviors a newcomer focuses on will depend on their initial levels of resources and will have 
implications for their rate of adjustment over time. For instance, those with more resources early on are more likely to engage in the socialization process (Ellis et al., 2015). These newcomers are more likely to demonstrate positive trajectories and growth because the early availability of resources makes it easier, and more likely, that they will readily acquire new resources. For example, a newcomer with early social connections may have greater access to information relevant to their job. Alternatively, those with fewer resources at the start of their tenure may be more concerned with the conservation, or protection, of resources, risking less and betting on safer, more conservative behavior early on (e.g., relying on established social relationships rather than attempting to forge new ones). Beyond their early tenure on the job, newcomers with greater initial resources may continue to expend those resources by investing in their own adjustment, thereby leading to a faster rate of adjustment over time than those with fewer initial resources at their disposal. Thus, we expect that greater resources at the onset of the socialization process will be associated with growth in adjustment over time.

Hypothesis 1: Newcomers with more resources upon entry will have better (a) levels of early adjustment and (b) rates of adjustment over time.

\section{Research Question: Which Resources Matter for Adjustment?}

We expect that greater resources will facilitate better adjustment overall. However, we also set out to develop an understanding of which resources matter most, as the mere existence of resources may not ultimately be sufficient for understanding the role resources play during socialization. As Hobfoll argues, "resources must fit the specific ecological demands inherent in the circumstances that confront individuals" (2002: 318). While we have outlined the role of resources in general, it is not clear whether specific resources might matter more or less for each of the three adjustment indicators initially or over time. Each adjustment indicator represents a unique aspect of newcomer socialization. Practically speaking, organizations should endeavor to promote all three indicators of 
adjustment. The ways in which early newcomer resources facilitate each of these adjustment indicators matters. The following highlights potential relationships based on our logical reasoning and past empirical findings. Absent clear and strong empirical and theoretical guidance, we present these relationships as research questions.

Material resources refer to the tools necessary to do one's work (Hobfoll, 2002). Having such resources available immediately should help to kick off the clarification process for new employees and help them start getting up to speed right away (Stibitz, 2015). Access to material resources facilitates information acquisition key to the learning process and reduces uncertainty which is central to the newcomer adjustment experience (Berger \& Calabrese, 1975). Early on, material resources could help newcomers feel more confident with higher task mastery and more accepted as they are able to more easily access information on all the dimensions of their jobs. Given the critical nature of material resources to job success, the organization is likely to support newcomer efforts to acquire these resources, meaning that any deficiencies in material resources initially may be quickly addressed by the organization, thus facilitating newcomer adjustment.

Personal resources (Ellis et al., 2015; Hobfoll, 1989) enable individuals to anticipate future demands, take steps to alleviate them, and seek out opportunities that facilitate their own adjustment (Kammeyer-Mueller \& Wanberg, 2003). They may be less likely to perceive a new job as a threat and are more resilient to potential setbacks during the adjustment process (Bauer \& Erdogan, 2014; Saks \& Gruman, 2011). Armed with these resources, newcomers may exhibit greater role clarity and mastery of their tasks early on, whereas a lack of these resources may indicate stunted adjustment over time comparatively.

Similarly, social resources include social support and the social network one has available to them. Jokisaari and Nurmi (2012) theorize that social resources should help new employees in several ways including understanding social schemas as well as newcomer access and ability to 
mobilize resources during their organizational socialization process. Fang, Duffy, and Shaw (2011) also posit that access to social resources (i.e., social capital) would be related to social integration and acceptance. Thus, social resources may be more likely to relate to early feelings of social acceptance, and over time enhance other aspects of adjustment. However, without direct facilitation from the organization, over time newcomers who start with initially lower levels of social resources may show slower adjustment than their high resource counterparts.

Finally, status resources (i.e., seniority or job level) may also be important. When individuals start a new job at a higher level, they are objectively higher in the organizational hierarchy, giving them greater access to authority, in part, through greater access to more experienced organizational insiders. For instance, Morrison (2002) found that the status of newcomers' informational network was positively related to adjustment, with the strongest relationships to newcomer task mastery. Rollag found that managerial level was associated with newcomer status. The author reasoned that those in higher levels may be, “...privy to more of the organization's goals, routines, and technologies, and... their promotion to a management position implies a higher level of general organizational competence" (2004: 860). This helps to build credibility. Status resources are also symbolically valuable to the extent they reinforce positive perceptions of the self (Hobfoll, 1989).

We investigated the following research question to determine if resources did indeed matter in some of the potential ways we have outlined. We also wanted to understand what form different pairings of newcomer resources and adjustment indicators took over time.

Research Question 1: Which newcomer resources (material, personal, social, and status resources) matter for specific aspects of early newcomer adjustment including (a) role clarity; (b) task mastery; (c) feelings of acceptance?

\section{Early Adjustment, Rate of Adjustment, and Manager Ratings of Adjustment}

Newcomers who experience higher early adjustment are likely to experience more positive outcomes and reactions from their managers, as these create more favorable early impressions (Allen 
et al., 2017; Ellis, Nifadkar, Bauer, \& Erdogan, 2017). Similarly, the rate of adjustment, or the trajectory of adjustment a newcomer experiences may also be associated with positive outcomes and reactions on the part of one's manager. Thus, those employees who experience positive growth in their adjustment, or those who report higher levels of positive change in their adjustment to their new jobs and the organization, will be more favorably received. Scholars have posited that newcomers who learn their new jobs quickly are more likely to be designated as high-potential employees. Regardless of job content, those employees who learn their jobs, adjust to their new roles, and acquire social status quickly, and therefore are on a more positive and steeper trajectory, are likely to be noticeable to insiders (Lombardo \& Eichinger, 2000); in contrast, those who experience fewer gains over time in their adjustment level run the risk of lower performance or even derailment (Jokisaari \& Nurmi, 2009; Kammeyer-Mueller, Wanberg, Rubenstein, \& Song, 2013). Employees who experience greater gains in adjustment over time are likely to be more visible to management. They will require less time and attention from management and coworkers as they are adjusting to their roles, and start producing results sooner (Bauer et al., 2007). As a result, we expect that growth in adjustment for newcomers will be positively associated with manager ratings of newcomer adjustment later on.

Hypothesis 2: Early newcomer adjustment for (a) role clarity, (b) task mastery, and (c) feelings of acceptance will be positively associated with later manager ratings of newcomer adjustment.

Hypothesis 3: Rate (i.e., slope) of newcomer adjustment for (a) role clarity, (b) task mastery, and (c) feelings of acceptance will be positively associated with later manager ratings of newcomer adjustment.

Given our hypotheses that the amount of resources newcomers possess upon organizational entry will facilitate early newcomer adjustment and rate of newcomer adjustment over time, and that early adjustment and rate of adjustment would facilitate later manager ratings of newcomer adjustment, it stands to reason that early adjustment and rate of adjustment would mediate the 
relationship between newcomer resources upon organizational entry and later newcomer adjustment. In other words, having resources available to newcomers early on will have indirect effects on how newcomers are rated by their managers over time, because newcomer access to resources will position them at an advantage with respect to adjusting to their new jobs early on, and will result in positive changes in their adjustment indicators over time such that their role clarity, task mastery, and feelings of acceptance will grow and improve more quickly. Having high levels of adjustment to one's job and showing early positive changes will make these newcomers more visible to their managers as adjusting quickly and well to their new positions.

Hypothesis 4: Early newcomer adjustment in terms of (a) role clarity, (b) task mastery, and (c) feelings of acceptance will mediate the relationship between newcomer resources and later manager ratings of newcomer adjustment.

Hypothesis 5: Rate (i.e., slope) of newcomer adjustment for (a) role clarity, (b) task mastery, and (c) feelings of acceptance will mediate the relationship between newcomer resources and later manager ratings of newcomer adjustment.

\section{METHOD}

\section{Sample, Design, and Procedures}

For three months, all new employees beginning work at the headquarters of a Fortune 500 technology organization were invited to participate in a longitudinal study. The time lags between data collections were held constant such that all new employees were surveyed at the same time in relation to their own post-entry time points. Newcomers completed online surveys on their first day at work and data were gathered from company records at T0. Subsequently, data were also gathered via online surveys sent to newcomers via internal company email after 1 month on the job (T1), 3 months on the job (T2), 6 months on the job (T3), and 9 months on the job (T4). At 9 months and 12 months (T5), managers rated newcomers in terms of their overall adjustment.

The company provided data for 1,055 new employees who were still employees 12 months post-hire and who had been invited to participate in the study. A total of 985 of these new employees 
agreed to participate, resulting in an initial response rate of $93 \%$. These individuals were $72 \%$ male and $27 \%$ female ( $1 \%$ did not respond to this question) and primarily Caucasian (67\% of the sample). New employees were hired into a variety of different jobs across job levels in three main areas of the organization including technology-related positions $(n=508)$, sales positions $(n=376)$, and general administrative positions $(n=101)$. Examples of jobs included entry-level engineers to UX engineers, sales agents, lawyers, recruiters, and compensation specialists. Our sample included job levels ranging from 1 to $7(M=3.62, S D=1.31)$. Finally, the 985 participants primarily had unique managers. Specifically, the average number of participants per manager was $1.28(S D=.77)$, and the intraclass correlations for modeled endogenous variables were all .00 with the exception of .15 for feelings of acceptance at 3 months. Given the small cluster sizes and intraclass correlations, the resulting size of the design effects ranged from 1.00 to 1.04 , which are quite low. As such, we did not account for participants clustered within managers in hypothesis testing. (See Appendix A for detailed information on response rates, missing data, and response-non-response analyses.)

\section{Measures}

Newcomer resource measures. Response scales ranged from $1=$ strongly disagree to $5=$ strongly agree unless noted. Resources were measured on day one (T0) from newcomers and company archival records, including past experiences, first day events, newcomer reports of personality, and whether friends and/or family worked in the organization. Material resources include how prepared the organization was for the newcomer on their first day on the job as indicated by having their workstation and computer "ready to go" upon their arrival. Had a work station assigned and available to them on their first day was coded $1=y e s$ and $0=$ no. Similarly, having their computer ready for them at orientation was coded $1=y e s$ and $0=$ no. Personal resources. Proactive personality was measured using nine items from the scale developed by Bateman and Crant (1993) ( $\alpha=.81)$. A sample item is "If I see something I don't like, I fix it." 
Optimistic personality was measured using the six-item Life Orientation Test by Scheier, Carver, and Bridges (1985) $(\alpha=.79)$. A sample item is "In uncertain times, I usually expect the best." Information regarding organizational knowledge (whether the newcomer had previously worked as a temporary or contract worker for this organization) was gathered from company records and coded as $1=$ yes and $0=n o$ ( 47 had previously worked for the organization). In addition, newcomers were asked about their previous work experience (measured in terms of whether or not this was the newcomer's first full-time, permanent job), and their responses were coded as $1=$ previous work experience and $0=$ no previous work experience. Of those who responded to this item, $68 \%(n=$ 549) reported that they had prior work experience. Social resources included insider relationships and manager availability on their first day on the job. To assess insider relationships, newcomers indicated if they had friends and/or family working at this organization $(1=y e s$ and $0=n o)$. If newcomers met their manager (met manager) on day one we coded this as a "1," and if they did not “0”. Status resources. We conceptualized newcomer job level as an indicator of status. Newcomer job level ranged between 1 and 7, with 7 being the most senior.

Measures of newcomer adjustment and adjustment over time. Newcomers reported adjustment four times (T1-T4) starting 1 month after entry. Role clarity (average $\alpha=.85$ ) was measured using five items from the role clarity scale developed by Rizzo, House, and Lirtzman (1970). A sample item includes "I know when I have divided my time properly." Task mastery (average $\alpha=.81$ ) was measured using a three-item scale (Bauer \& Green, 1998) assessing their confidence to successfully engage in the tasks of their role. A sample item includes "I am confident in my ability to do my job." Feelings of acceptance (average $\alpha=.83$ ) was measured using three positively worded items from Fey (1955). A sample item includes "My coworkers seem to like me." 
Manager ratings of newcomer adjustment. This captured managers' perception of newcomer adjustment at 9 and 12 months post-entry. Manager ratings were measured using a six-item composite scale created by the organization to assess how well newcomers had adjusted toward the end of their first year. The response scale for this measure ranged from $1=$ never/rarely to $5=$ always. Sample items include: "[Name] finds the information needed to do his/her job." and "[Name] is a fully contributing member of the team."

\section{Data Analysis Strategy}

All models were estimated using the R lavaan package version 0.5-20 (Rosseel, 2012) using full information maximum likelihood. To examine adjustment over time, we applied a series of latent growth models (LGMs), wherein the slope and the intercept were modeled as latent factors (McArdle \& Nesselroade, 2014; Newsom, 2015). LGM provides an analytical framework for examining between-individual differences in change over time by assessing the variability of change trajectories across individuals and their associations with time-invariant predictors or outcomes. An unconditional LGM provides estimates of the average early level (i.e., intercept factor) and average growth (i.e., slope factor) across individuals, as well as the variances of these factors and the covariance between them. We specified conditional LGMs that included time-invariant predictor and outcome variables (Curran, Bauer, \& Willoughby, 2004). To estimate indirect effects for Hypotheses 4 and 5, we used percentile bootstrapping with 2,000 resamples to construct 95\% confidence intervals (CIs). Unstandardized estimates are reported throughout.

\section{RESULTS}

\section{Preliminary Analyses}

We provide the between- and within-person correlations, means, and standard deviations for focal variables in Table 1. (See Appendix B for descriptive statistics for each of the adjustment variables at each time period.) As can be seen in Appendix B, the average of every adjustment 
variable was higher at the latest data collection point whether it was rated by newcomers or their managers. Prior to hypothesis testing, we performed preliminary model tests. First, to interpret LGMs in a meaningful manner, evidence of measurement invariance is needed (Lance, Meade, \& Williamson, 2000; Vandenberg \& Lance, 2000). Briefly, role clarity and task mastery showed evidence of configural and metric invariance, and partial scalar and uniqueness invariance; and acceptance showed evidence of configural, metric, and scalar invariance, and partial uniqueness invariance. We used the resulting best-fitting second-order models for subsequent models associated with assessing functional form and hypothesis testing. (See Appendix C for a detailed description of the measurement invariance testing process.) Second, using nested model comparisons, we determined whether a linear, quadratic, or cubic functional form for each adjustment indicator's unconditional LGM was most appropriate given the data. Briefly, a linear functional form showed good fit to each adjustment indicator's LGM, and adding a quadratic factor did not improve the fit for role clarity or task mastery. For acceptance, a quadratic factor did improve model fit. Models specified with a cubic factor were all non-positive definite, and the results were not reported. For reasons of consistency and parsimony, we retained the linear unconditional LGM for all three adjustment indicators. (See Appendix D for a detailed description of this process.) Third, the three linear unconditional LGMs showed adequate fit to the data: role clarity $\left(\chi^{2}=256.42, d f=169, \mathrm{CFI}=\right.$ $.99, \mathrm{TLI}=.99, \mathrm{RMSEA}=.02, \mathrm{RMSEA} 90 \% \mathrm{CI}[.02, .03], \mathrm{SRMR}=.04)$, task mastery $\left(\chi^{2}=82.898\right.$, $d f=45, \mathrm{CFI}=.99, \mathrm{TLI}=.99, \mathrm{RMSEA}=.03, \mathrm{RMSEA} 90 \% \mathrm{CI}[.02, .04], \mathrm{SRMR}=.04)$, and acceptance $\left(\chi^{2}=70.656, d f=51, \mathrm{CFI}=1.00, \mathrm{TLI}=.99, \mathrm{RMSEA}=.02, \mathrm{RMSEA} 90 \% \mathrm{CI}[.01, .03]\right.$, SRMR $=.06) .{ }^{1}$ The means of the slope factors (i.e., trajectories) were all positive and significant (role clarity: $\mu=.262, p<.001$; task mastery: $\mu=.272, p<.001$; acceptance: $\mu=.271, p<.001$ ),

\footnotetext{
1 We applied conventional cutoff values for CFI $(\geq .95)$, TLI $(\geq .95)$, RMSEA $(\leq .06)$, and SRMR $(\leq .08)($ Hu \& Bentler, 1999).
} 
indicating that in general newcomers' adjustment improved over their first 9 months. In addition, there was evidence of significant between-person variability in trajectories (role clarity: $\sigma=.002, p<$ .001 ; task mastery: $\sigma=.001, p<.05$; acceptance: $\sigma=.001, p<.01)$, indicating the likely existence of time-invariant predictors (between-person moderators). Regarding the intercept factors, the means and variances were all significant (role clarity: $\mu=2.278, p<.001, \sigma=.185, p<.001$; task mastery: $\mu=2.570, p<.001, \sigma=.211, p<.001$; acceptance: $\mu=2.556, p<.001, \sigma=.143, p<.001)$. Finally, the covariance between the intercept and slope factors for role clarity was significant and negative (role clarity: $\psi=-.008, p<.001$ ), and the covariances for task mastery and acceptance were nonsignificant (task mastery: $\psi=-.004, p=.06$; acceptance: $\psi=-.003, p=.08$ ).

\section{Hypothesis 1 and Research Question 1}

For Hypothesis 1, we predicted that the greater resources that a newcomer possessed upon entry, the better their adjustment (role clarity, task mastery, acceptance) would be in terms of (a) early levels of adjustment and (b) rate of adjustment over time. Research Question 1 concerned the unique relationships between specific early resources and the different adjustment indicators. Although these are theoretically distinct questions, they rely on the same overall set of analyses; therefore, we present the results for both in this first section, followed by the results for Hypotheses 2-5 in subsequent sections. To test Hypotheses $1 \mathrm{a}$ and 1b, we constructed and tested three conditional LGMs - one for each of the three adjustment variables (i.e., aspects of adjustment). We set the linear slope factor loadings to $0,2,5$, and 8 (i.e., 1 month, 3 months, 6 months, 9 months). In these models, we freely estimated the covariance between slope and intercept factors, and included all resource variables as time-invariant exogenous variables. Using these models, we tested the associations between the nine resource variables and the estimated adjustment-variable intercepts (i.e., early levels) and slopes (i.e., trajectories, rates of change) (see Table 2). All three models demonstrated adequate fit to the data: Model fit information: role clarity $\left(\chi^{2}=445.35, d f=331, \mathrm{CFI}=.98, \mathrm{TLI}=.98, \mathrm{RMSEA}=.02\right.$, 
RMSEA 90\% CI[.01, .02], SRMR $=.03)$, task mastery $\left(\chi^{2}=189.89, d f=135, \mathrm{CFI}=.99, \mathrm{TLI}=.99\right.$, RMSEA $=.02$, RMSEA 90\% CI[.01, .03], SRMR $=.03)$, and acceptance $\left(\chi^{2}=179.19, d f=141\right.$, CFI $=.99, \mathrm{TLI}=.99, \mathrm{RMSEA}=.02, \mathrm{RMSEA} 90 \% \mathrm{CI}[.01, .02], \mathrm{SRMR}=.03)$.

Early levels of role clarity. Greater levels of the following resources were associated with higher early levels of role clarity overall with a $R^{2}$ of .21 . In terms of specific relationships (Research Question 1a), proactive personality $(b=.18, p<.001)$, optimistic personality $(b=.20, p<.001)$, organizational knowledge $(b=.36, p<.001)$, and having a work station ready on the first day $(b=$ $.16, p<.05)$ were significantly related to early role clarity. The following resources were not associated with early levels of role clarity: previous work experience $(b=.03, p=.443)$, having a computer ready $(b=.03, p=.776)$, having insider relationships $(b=-.03, p=.414)$, having met a manager on the first day $(b=.00, p=.966)$, and newcomer job level $(b=.00, p=.976)$.

Early levels of task mastery. Greater levels of the following resources were associated with higher early levels of task mastery overall with a $R^{2}$ of .35. Addressing Research Question 1b, proactive personality $(b=.44, p<.001)$, optimistic personality $(b=.16, p<.001)$, and organizational knowledge $(b=.32, p<.001)$ were related to early task mastery. The following resources were not associated with early levels of task mastery: previous work experience $(b=.01, p$ $=.800)$, having a work station ready $(b=-.02, p=.729)$, having a computer ready $(b=-.03, p=$ $.791)$, having insider relationships $(b=-.02, p=.626)$, having met a manager on the first day $(b=$ $.09, p=.067)$, and newcomer job level $(b=.01, p=.359)$.

Early levels of feelings of acceptance. Overall, greater levels of resources were associated with higher early levels of feelings of acceptance with one exception with a $R^{2}$ of .25 . For Research Question 1c, proactive personality $(b=.23, p<.001)$, optimistic personality $(b=.17, p<.001)$, organizational knowledge $(b=.36, p<.001)$, and having met a manager on the first day $(b=.10, p<$ .05) were related to higher feelings of acceptance. The resource of newcomer job level was 
negatively associated with early acceptance $(b=-.03, p<.05)$, such that newcomers with higher job levels upon entry tended to have lower levels of early acceptance. The following resources were not associated with early levels of acceptance: organizational knowledge $(b=.10, p=.188)$, previous work experience $(b=-.06, p=.139)$, having a work station reading on the first day $(b=.03, p=$ $.655)$, having a computer ready on the first day $(b=-.07, p=.435)$, and having insider relationships on the first day $(b=-.04, p=.301)$.

Summary of Hypothesis 1a results. Overall, Hypothesis 1a received support in that resources generally showed positive or null associations to early adjustment indicating that they support the socialization of newcomers, but when interpreting the specific resources, we found partial and mixed support which we explored further in Research Question 1a-c. Personal resources of greater proactive personality and optimistic personality were associated with higher early levels of role clarity, task mastery, and acceptance, and greater organizational knowledge was associated with early levels of role clarity and acceptance. Having a work station ready on the first day, a material resource, was also associated with early levels of adjustment - but only for role clarity. The social resource of having met a manager on the first day was also associated with early levels of adjustment - but only for feelings of acceptance. Unexpectedly, the status resource of newcomer job level was negatively associated with early levels of acceptance, such that newcomers with higher job levels upon entry tended to have lower levels of early acceptance. None of the other resources was associated with early levels of adjustment.

Hypothesis 1b. For Hypothesis 1b, we predicted that the greater resources that a newcomer possessed upon entry, the better their rate of adjustment over time would be. The results below are organized by adjustment indicator in this order: role clarity, task mastery, and acceptance.

Rate of adjustment of role clarity. Unexpectedly, greater levels of the following resources were associated with slower rates of the role clarity aspect of adjustment (i.e., slope of role clarity): 
proactive personality $(b=-.02, p<.05)$, organizational knowledge $(b=-.03, p<.05)$, and having a work station ready on the first day $(b=-.02, p<.05)$. The following resources were not associated with slope of role clarity in either direction: optimistic personality $(b=-.00, p=.930)$, previous work experience $(b=.00, p=.986)$, having a computer ready on the first day $(b=.00, p=.797)$, having insider relationships on the first day $(b=.01, p=.447)$, having met a manager on the first day $(b=-.00, p=.855)$, and newcomer job level $(b=-.00, p=.183)$.

Rate of adjustment of task mastery. Unexpectedly, a greater level of proactive personality was associated with slower rates of the task mastery aspect of adjustment (i.e., slope of task mastery) $(b=-.02, p<.05)$. The following resources were not associated with slope of task mastery in either direction: optimistic personality $(b=.00, p=.522)$, organizational knowledge $(b=-.02, p=.211)$, previous work experience $(b=.01, p=.232)$, having a work station ready on the first day $(b=-.00, p$ $=.903)$, computer ready on the first day $(b=.02, p=.210)$, having insider relationships on the first day $(b=.00, p=.988)$, having met a manager on the first day $(b=-.01, p=.174)$, and newcomer job level $(b=-.00, p=.416)$.

Rate of adjustment of feelings of acceptance. Unexpectedly, greater levels of the following resources were associated with slower rates of the feelings of acceptance aspect of adjustment (i.e., slope of acceptance): proactive personality $(b=-.02, p<.05)$ and having a work station ready on the first day $(b=-.02, p<.05)$. The following resources were not associated with slope of acceptance in either direction: optimistic personality $(b=.00, p=.638)$, organizational knowledge $(b=-.02, p=$ $.056)$, previous work experience $(b=-.01, p=.493)$, having a computer ready on the first day $(b=$ $.03, p=.060)$, having insider relationships on the first day $(b=.01, p=.239)$, having met a manager on the first day $(b=-.01, p=.173)$, and newcomer job level $(b=.00, p=.891)$.

Summary of Hypothesis $1 \mathrm{~b}$ results. Overall, Hypothesis $1 \mathrm{~b}$ was not supported, and all significant associations between resources and rate of adjustment were negative, which was contrary 
to our prediction that greater resources would lead to better rates of adjustment. Namely, greater proactive personality was associated with slower rates of adjustment in terms of role clarity, task mastery, and acceptance. Next, having a work station ready on the first day was associated with a slower rate of adjustment in terms of role clarity and acceptance. Finally, having organizational knowledge was associated with a slower rate of the role clarity aspect of adjustment. The other newcomer resources were not associated with rate adjustment.

\section{Post-hoc Analyses}

Our results for Hypothesis $1 \mathrm{~b}$ suggested that the nature of the relationship between newcomer resources and adjustment trajectories did not follow a simple positive pattern. As a result, we probed these relationships further in a series of post-hoc analyses. Specifically, we operationalized patterns of newcomer adjustment using the following three characteristics, which resulted from regressing LGM intercept and slope factors on time-invariant resource variables: (1) adjustment intercept differences at 1 month (i.e., differences in early adjustment), (2) slope of adjustment differences from 1 month to 9 months (i.e., differences in rate of adjustment over time), and (3) adjustment intercept differences at 9 months (i.e., differences in later adjustment). We describe these three characteristics and how we examined them in greater detail in Appendix E.

Patterns were observed in the rate of change in adjustment aspects that were associated with personal resources. Both proactive personality and organizational knowledge demonstrated similar patterns in that those with lower early levels of these resources showed a faster, more positive rate of change in role clarity and eventually "caught up" to those newcomers with greater early levels. (Please see Figure 2 for a visual summary of the patterns that emerged.) Those with lower early levels of these resources also showed positive gains in task mastery; however, lower levels of proactive personality was associated with a significantly more positive rate of change in task mastery, whereas the lack of organizational knowledge was not associated with differences in rate of 
change in task mastery. Lower proactive personality was also associated with a more positive rate of change in feelings of acceptance. Optimism, another personal resource, demonstrated a different pattern of adjustment. In this case, those with lower early levels of optimism showed similar rates of adjustment with respect to all three adjustment aspects as compared to those with greater early levels. Some significant relationships were also found for the other types of resources; however, these patterns were less clear. What is clear is that variation is especially evident in those newcomers starting off with fewer resources.

\section{Hypotheses 2 and 3}

For Hypothesis 2, we predicted that newcomer early adjustment for (a) role clarity, (b) task mastery, and (c) feelings of acceptance would predict later manager ratings of adjustment, and for Hypothesis 3, we predicted that newcomer slope of adjustment for (a) role clarity, (b) task mastery, and (c) feelings of acceptance would predict later manager ratings of adjustment. To test these hypotheses, we specified six conditional LGMs corresponding to the three time-varying adjustment indicators (i.e., role clarity, task mastery, acceptance) and manager ratings of adjustment (see Table 3). In each model, we regressed time-invariant manager ratings of adjustment at either 9 or 12 months on the early adjustment (intercept) and slope of adjustment latent factors.

First, we estimated the effect of early level of adjustment (intercept) and slope of adjustment for each of the three adjustment indicators (i.e., role clarity, task mastery, feelings of acceptance) - on manager ratings of adjustment at 9 months. Model fit to the data was acceptable for each of the three models: role clarity $\left(\chi^{2}=278.92, d f=189, \mathrm{CFI}=.99, \mathrm{TLI}=.99, \mathrm{RMSEA}=.02, \mathrm{RMSEA} 90 \%\right.$ $\mathrm{CI}[.02, .03], \mathrm{SRMR}=.04)$, task mastery $\left(\chi^{2}=102.75, d f=57, \mathrm{CFI}=.99, \mathrm{TLI}=.99, \mathrm{RMSEA}=.03\right.$, RMSEA 90\% CI[.02, .04], SRMR $=.04)$, and acceptance $\left(\chi^{2}=76.84, d f=63, \mathrm{CFI}=1.00, \mathrm{TLI}=\right.$ 1.00, RMSEA $=.02$, RMSEA 90\% CI[.00, .03], SRMR = .04). Providing initial support for Hypotheses 2a, 2b, and 2c, newcomers with higher early role clarity, task mastery, and acceptance 
received higher manager ratings of adjustment at 9 months $(b=.17, p<.01 ; b=.22, p<.01 ; b=.15$, $p<.05$, respectively) (see Table 3 ). In support of Hypotheses $3 \mathrm{a}$ and $3 \mathrm{c}$, those with faster role clarity and acceptance growth over the first 9 months received higher ratings of adjustment from their managers at 9 months $(b=2.54, p<.05$ and $b=3.37,<.05$, respectively). Hypothesis $3 b$ was not supported, as task mastery growth was not significantly associated with manager ratings of adjustment at 9 months $(b=3.47, p=.084)$.

To test Hypotheses 2 further, we estimated the effect of early level of adjustment (intercept) and slope of adjustment - for each of the three adjustment indicators - on manager ratings of adjustment at 12 months. Model fit to the data was acceptable for each of the three models: role clarity $\left(\chi^{2}=272.94, d f=189, \mathrm{CFI}=.99, \mathrm{TLI}=.99, \mathrm{RMSEA}=.02, \mathrm{RMSEA} 90 \% \mathrm{CI}[.02, .03]\right.$, $\mathrm{SRMR}=.04)$, task mastery $\left(\chi^{2}=94.35, d f=57, \mathrm{CFI}=.99, \mathrm{TLI}=.99, \mathrm{RMSEA}=.03, \mathrm{RMSEA} 90 \%\right.$ CI $[.02, .04]$, SRMR $=.04)$, and acceptance $\left(\chi^{2}=85.14, d f=63\right.$, CFI $=1.00$, TLI $=.99$, RMSEA $=$ .02 , RMSEA 90\% CI[.01, .03], SRMR =.04). Early role clarity, task mastery, and acceptance were not associated with manager ratings of adjustment at 12 months $(b=.10, p=.124 ; b=.10, p=.120$; $b=.12, p=.084$, respectively), thereby failing to find support for Hypotheses $2 \mathrm{a}, 2 \mathrm{~b}$, and $2 \mathrm{c}$ at 12 months. In support of Hypothesis 3a, those with faster role clarity growth received higher manager ratings of adjustment at 12 months $(b=2.32, p<.05)$; however, task mastery and acceptance growth were not associated with manager ratings of adjustment at 12 months $(b=2.96, p=.144$ and $b=$ $1.37, p=.294$, respectively), thereby failing to find support for Hypothesis $3 \mathrm{~b}$ and $3 \mathrm{c}$ at 12 months.

Overall, Hypothesis 3a received full support; Hypotheses 2a, 2b, 2c, and 3c received partial support; and Hypothesis $3 \mathrm{~b}$ did not receive support. In other words, with the exception of slope of task mastery, newcomer early levels of adjustment and the rates at which they adjusted were associated with manager ratings of adjustment at 9 months. In contrast, only the rate of adjustment in terms of role clarity was associated with manager ratings of adjustment at 12 months. 


\section{Hypotheses 4 and 5}

For Hypotheses 4 and 5, we predicted that early newcomer adjustment for (a) role clarity, (b) task mastery, and (c) feelings of acceptance and the slope of adjustment indicators, respectively, would mediate the relationship between newcomer personal, social, material, and status resources and later manager ratings of newcomer adjustment. That is, we expected newcomers with greater resources early on in their tenure would be rated higher in adjustment at 9 and 12 months by their manager, due to higher early adjustment and a faster rate of adjustment over the first 9 months. To test this, we specified six conditional LGMs corresponding to the three time-varying adjustment indicators (i.e., role clarity, task mastery, acceptance) and manager ratings of adjustment. We specified the early adjustment (intercept) and slope of adjustment latent factors as mediators of the associations between the time-invariant resource variables and manager ratings of adjustment.

In the first three models, we estimated the indirect effects of the resource variables on manager ratings of adjustment at 9 months via early level (intercept) of adjustment and slope of adjustment. Model fit to the data was acceptable for each of the three models: role clarity $\left(\chi^{2}=478.47, d f=352\right.$, $\mathrm{CFI}=.98, \mathrm{TLI}=.98, \mathrm{RMSEA}=.02, \mathrm{RMSEA} 90 \% \mathrm{CI}[.02, .02]$, SRMR $=.04)$, task mastery $\left(\chi^{2}=\right.$ 212.27, $d f=148, \mathrm{CFI}=.99, \mathrm{TLI}=.98, \mathrm{RMSEA}=.02, \mathrm{RMSEA} 90 \% \mathrm{CI}[.01, .03], \mathrm{SRMR}=.04)$, and acceptance $\left(\chi^{2}=186.86, d f=154, \mathrm{CFI}=.99, \mathrm{TLI}=.99, \mathrm{RMSEA}=.02, \mathrm{RMSEA} 90 \% \mathrm{CI}[.00, .02]\right.$, SRMR =.03). With four exceptions, all of the $95 \%$ confidence intervals (CIs) for the indirect effects included zero, indicating that they were nonsignificant. Namely, the indirect effects of the personal resources of proactive personality, optimistic personality, and prior organizational knowledge on manager ratings of adjustment at 9 months via early task mastery were positive and significant $(95 \%$ CI[.018, .170], CI[.006, .072], CI[.012, .135], respectively). That is, early task mastery mediated the effect of some personal resources on manager ratings of adjustment at 9 months, which provided partial support for Hypothesis 4b. In addition, the indirect effect for the material resource of having a 
computer ready on manager ratings of adjustment at 9 months via the slope of acceptance was positive and significant $(95 \% \mathrm{CI}[.004, .667])$, which provided partial support for Hypothesis 5c. Hypotheses 4a, 4c, 5a, and 5b were not supported.

In the second three models, we estimated the indirect effects of the nine resource variables on manager ratings of adjustment at 12 months via the early level (intercept) of adjustment and slope of adjustment. Model fit to the data was acceptable for each of the three models: role clarity $\left(\chi^{2}=\right.$ 468.61 $, d f=352, \mathrm{CFI}=.98, \mathrm{TLI}=.98, \mathrm{RMSEA}=.02, \mathrm{RMSEA} 90 \% \mathrm{CI}[.01, .02], \mathrm{SRMR}=.04)$, task mastery $\left(\chi^{2}=203.72, d f=148, \mathrm{CFI}=.99, \mathrm{TLI}=.99, \mathrm{RMSEA}=.02, \mathrm{RMSEA} 90 \% \mathrm{CI}[.01, .02]\right.$, $\operatorname{SRMR}=.03)$, and acceptance $\left(\chi^{2}=193.32, d f=154, \mathrm{CFI}=.99, \mathrm{TLI}=.99, \mathrm{RMSEA}=.02, \mathrm{RMSEA}\right.$ $90 \% \mathrm{CI}[.01, .02], \mathrm{SRMR}=.03$ ). All of the $95 \%$ confidence intervals (CIs) for the indirect effects included zero, which indicates that Hypotheses 4 and 5 did not receive support when manager ratings of adjustment were assessed at 12 months. Overall, Hypothesis $4 \mathrm{~b}$ and $5 \mathrm{c}$ received limited support, and Hypotheses 4a, 4c, 5a, and 5b were not supported. Similar to Hypotheses 2 and 3, more support was found for Hypotheses 4 and 5 when manager ratings were assessed at 9 months as opposed to 12 months.

\section{DISCUSSION}

The resources that new employees bring with them to a new organization does not happen by accident. Which new employees join an organization with specific resources upon entry is a direct outcome of the recruitment and selection process. Overall, our study provides new insights to the nature of the relationship between newcomer resources and newcomer adjustment. Specifically, we found that the availability of specific resources (e.g., proactive personality) and certain types of resources (e.g., personal resources) newcomers had upon organizational entry improved their early levels of adjustment, and these higher early levels of adjustment led to more favorable manager ratings of adjustment 9 months post entry. In short, early resources were indeed associated with how 
newcomers perceived and reported their adjustment. We also found that for some aspects of adjustment (i.e., role clarity, task mastery), faster rates of adjustment were associated with higher manager ratings of adjustment at 9 months post-entry. Thus, resources appeared to influence adjustment as perceived by both newcomers and their managers. We also found that the average of every adjustment variable was higher at the latest data collection point whether it was rated by the newcomers or their managers indicating that time was on newcomers' side and was related, overall, to higher adjustment levels.

When considering newcomers' resource availability in relation to change in adjustment over time, however, the pattern of relationships became more complicated. This was both puzzling and one of the more intriguing aspects of our analyses and results. When we evaluated how access to resources may lead to differences in early adjustment, rate of adjustment over time, and later adjustment, we identified six qualitatively different patterns of adjustment. With some exceptions, newcomers who had higher levels of certain initial resources tended to have higher early adjustment compared to those who had lower levels. For some resource-adjustment aspect combinations, higher levels of initial resources subsequently led to a slower rate of adjustment, resulting in a narrowing of the adjustment gap by end of the first 9 months. In contrast, for other combinations, higher levels of initial resources subsequently led to similar rates of adjustment and perpetuated the early adjustment gap through the first 9 months. These findings speak to the complex role that resources may play in the adjustment process, which we are just scratching the surface in this study. The following points to specific theoretical and practical implications of our study and where we hope to see this line of research continue.

\section{Theoretical Implications}

The availability of resources on the first day was generally related to early adjustment. This is consistent with the notion that resources matter and matter differentially. However, our results also 
suggest that the simple availability of resources is not the entire story in terms of employees' adjustment over time. Specifically, in some instances, even those with somewhat lower availability of resources early on were able to close the gap to those who started with higher levels of resources. As noted, one possible explanation for this effect is that employees may make individual efforts to build and acquire resources in the face of loss or threatened loss of resources. Indeed, support for newcomers' role in the adjustment process has been consistently found (Ashford \& Black, 1996; Ellis et al., 2017). Unfortunately, our study was not able to examine individual newcomer behaviors, but it seems probable that a lack of resources on the first day on the job could lead certain individuals to proactively seek out resources which might explain the more rapid increases in perceived adjustment compared to those who start with higher resources. Future research that examines these behaviors in the context of perceived resource availability would help to address this possibility.

When examining specific early resources, we found that not all resources are created equally or demonstrated the same relationships to later adjustment. Different resources may carry different meanings and/or utility in different contexts. For example, having one's work station ready may be a material resource and facilitate task adjustment, but also carry symbolic value because it suggests that the organization values and cares about the newcomer, increasing feelings of belongingness. In other words, material resources may carry nonmaterial benefits. Relatedly, one of our resource indicators, having one's computer set up on the first day on the job, had low variance with $96 \%$ of the sample indicating that they had this. Thus, of the 985 people, less than 40 weren't provided with a computer on day 1 . Given that our study was conducted in the technology industry, in retrospect, this finding was not surprising. This high base rate likely contributed to the significant but relatively low correlation (.09) with the other material resource and the lack of results for the hypothesis tests with this indicator included. Further, because resources are somewhat idiosyncratic as they become 
valuable depending on the larger context and demands within that context, a necessary step for socialization researchers is to identify what aspects of the context matter and what resources become valuable within that context. This is an important challenge. It is likely that the categorization or type of resource may be generalizable across organizations and their socialization processes, while some of the specific resources and their measurement would need to be altered to fit a specific organization and its practices/policies (this is the approach we've taken in this study). We believe our study has taken an important step in this direction, and can serve as a foundation to future work in this area.

COR theory suggests that the threat of loss or actual loss of resources is not only stressful for newcomers, but should motivate behaviors aimed at managing resource levels, especially when the need to adjust and effectively meet demands is critical. The desire to restore resource levels and avoid further loss could motivate some newcomers to make investments that lead to resource gains which result in increases in adjustment. That is, compared to newcomers who start with substantial resources and demonstrate correspondingly steady increases in adjustment, those starting with lower resources may make early investments and take risks that result in positive gains over time. These gains in resources could occur rapidly when they are supported and reinforced by the organization, such that newcomers actually catch up to those with initially higher resources, or may occur steadily and gradually demonstrating the parallel pattern to those with initially higher resources that we observed. It is also plausible that newcomers starting with lower resources make no investment in future resource gains and focus on maintaining or conserving current resources.

Researchers have lamented the lack of explicit theories and research designs aimed at understanding the role of time in research in general (George \& Jones, 2000) and in socialization studies in particular (Ashforth, 2012) and our study addressed time explicitly by examining adjustment over the first year in terms of adjustment levels over time as well as trajectories. 
Additionally, it is interesting to examine which factors were not related to adjustment over time. We found that insider relationships on the first day did not matter in the context of the larger model. However, meeting one's manager on the first day did matter for early feelings of acceptance. Thus, there is more work to be done to understand the nuances of when and why different newcomer relationships matter for new employee adjustment (Kammeyer-Mueller et al., 2013; Nifadkar, 2020). On the other hand, it is reassuring that at least in this particular organization, having friends or family working there prior to organizational-entry was not related to specific adjustment advantages. This lack of nepotism or favoritism is encouraging, especially given that nepotism is associated with accelerated nonmerit-based decisions made within organizations. We do not know if this finding would hold in other organizations. Thus, it makes sense to retain this aspect of resources in future tests of our model.

Another aspect related to time in our study was the difference in manager ratings of adjustment at 9 months versus 12 months. It appears that as the time from organizational entry was longer, the influence of early adjustment became less and less salient. Had we not gathered data at 9 months, we might have missed an important finding and concluded that newcomer and manager ratings of adjustment are unrelated. However, we found that at 9 months, they were. Thus, our study shows it is important to continue to carefully consider the timing of data collection in socialization research (Bauer, Morrison, \& Callister, 1998).

Further, we added to our understanding of how adjustment varies over time within newcomers. This work builds upon what we know about how the job satisfaction of newcomers changes over time (Boswell, Shipp, Payne, \& Culbertson, 2009). Job attitudes are important and do vary across the adjustment period, and the organizational socialization literature has often theorized job attitudes as outcomes of adjustment with newcomer adjustment indicators serving as mediating variables which tend to precede the job attitudes and behaviors of newcomers (Allen et al., 2017; Bauer et al., 
2007; Saks et al., 2007). Thus, showing that adjustment varies over time as well, and does so based on newcomer resources, adds to our theoretical understanding of both resource conservation and the socialization adjustment process.

Finally, to our knowledge, no study of organizational socialization has gathered information regarding adjustment from an important organizational insider - the manager - in order to see how newcomers' self-ratings of adjustment influence insider perceptions of their adjustment. This lack of an insider view is a curious omission in our understanding of the newcomer socialization process as newcomers' own perceptions may or may not be consistent with those of insiders, and insider views of adjustment are likely to be associated with tangible rewards and opportunities for the newcomer. Managers' views regarding employee adjustment matter, because managers' perception that the employee is up to speed will arguably shape their reactions to the employee, how much they delegate or challenge the employee, and what kind of a career path they create for the employee (Ellis et al., 2017). Manager perceptions of newcomer adjustment are consequential because managers are more likely to take actions benefiting the newcomer and put them on the path for success within the company if they feel that the newcomer is now an insider. Our model makes a contribution by exploring how resources available to the newcomer influence the different adjustment patterns newcomers experience and how the adjustment patterns ultimately relate to manager ratings of newcomer adjustment, providing a close look at the current black box between resources and eventual success in the socialization process.

\section{Practical Implications}

As we share potential practical implications of our findings, we do want to point out that our large sample size, by default, means that some of our significant findings are still based on relatively small in practical significance. Nonetheless, the findings of our study do have practical implications. In terms of ultimate newcomer adjustment, we find that it is newcomers' early role clarity, feelings of acceptance, 
and task mastery, and their rate of role clarity and feelings of acceptance growth that relate to managerrated adjustment at 9 months post-entry. This gives an indication that organizations should focus on establishing role clarity, task mastery, and feelings of acceptance early on during a new employee's tenure and after that is in place, focus on the growth of their role clarity and feelings of acceptance. With respect to feelings of acceptance specifically, this is consistent with Nifadkar and Bauer (2016) who found that newcomers who were unable to establish meaningful connections with coworkers sought less information from them. But, that if a newcomer and their manager were able to connect, the newcomer was able to compensate for the weaker relationship with coworkers. The relationship the new employee has with their manager alleviated the problem as the new employee felt they belonged somewhere in the organization.

In reviewing the results of the most potent resources, it is clear that personal resources play an important role as they were consistently related to early newcomer adjustment. Proactive personality and optimistic personality most consistently predicted the pattern of newcomer adjustment; although, as discussed earlier, the patterns of adjustment differ with respect to which adjustment indicator is the focus. This has practical implications for organizational socialization. It has previously been established, for example, that proactive personality (e.g., Kammeyer-Mueller \& Wanberg, 2003; Simon, Bauer, Erdogan, \& Shepherd, 2019) is important for newcomer adjustment, but this study is the first to establish that proactive personality levels relate to differences in early adjustment as well as adjustment patterns over time. Thus, we have extended the findings of previous work to show that it is both the intercept and the slope of adjustment that are influenced by this personality characteristic. Given this consistent and extended finding, we encourage organizations to consider how they can best encourage proactivity and engagement among newcomers. One potential avenue is to employ strategic nudges to both managers and employees sharing research findings such as these. 
With respect to other personal resources, possessing prior organizational knowledge led to higher early adjustment in terms of role clarity and task mastery. At the same time, those without prior organizational knowledge had a faster rate of adjustment in terms of role clarity, and eventually caught up to those who possessed prior organizational knowledge on the first day. Similar to optimistic personality, those who possessed organizational knowledge had higher early task mastery and after 9 months still had higher task mastery than those who did not possess prior organizational knowledge on the first day. This indicates that those individuals who were formerly contractors or temporary employees at this organization did have an easier time adjusting but that it did not seem to either help or hurt their acceptance within the organizations once they arrived as full-time employees. Thus, from a practical perspective, all things being equal, organizations might consider temporary assignments as helpful in facilitating adjustment and worth exploring further as a potential avenue for newcomer adjustment and onboarding.

Finally, our findings have implications for organizations and managers, as material resources also appeared to play a role in early adjustment and adjustment growth. Specifically, having a work station on the first day led to early higher levels of role clarity; however, those who lacked a work station on the first day eventually caught up in terms of their role clarity. So, while it is helpful, other factors matter more once the newcomer begins his or her actual work. Based on these results, it is important to appropriately resource managers to allow them to ensure that the material resources such as having a work station ready to go on the first day of the job are important aspects to early and later adjustment. However, while this is optimal, it may not be mission-critical as newcomers seem to overcome this in the long run. While not as salient as personal resources, these were important as well so that missing the opportunity to get things off to a good start is something to be avoided. Organizations might consider encouraging and rewarding managers who are able to consistently create first day experiences that help newcomers hit the ground running and help them 
feel more accepted over time. One way to do this is to ask new employees about their early experiences as a form of quality control on these actions being taken competently.

\section{Potential Limitations and Future Research}

While this study did employ a longitudinal design spanning a year, it is still possible that different time frames between data collections would uncover different results. As scholars have acknowledged, our six data collection points (first day through 12 months) included commonly employed time demarcations in socialization research (Bauer et al., 1998; Boswell et al., 2009), but it is not clear if these time frames are granular enough to pick up on the nuances of adjustment and how resources influenced the process of socialization. Thus, we agree with Boswell et al.'s (2009) suggestion to include shorter, more intensive data collections in future research. While the present study was able to detect changes over the course of several months, there may be questions that can best be answered in the context of more frequent data collections such as daily and weekly event sampling. For example, how do daily stressors influence gains in perceptions of adjustment?

In addition, the relatively limited amount of research that has taken a more dynamic and longitudinal approach to the socialization process, has tended to focus on variability in adjustment or job satisfaction (e.g., Boswell et al., 2009; Chen, Ployhart, Thomas, Anderson, \& Bliese, 2011; Jokisaari \& Nurmi, 2009), but has not examined patterns of resource and adjustment over time (e.g., Chan \& Schmitt, 2000; Kammeyer-Mueller et al., 2013). This is surprising given that organizational entry is a seemingly ideal situation to study patterns, as a true "starting" point exists. However, in the case where new employees started out with fewer resources but never "caught up" with those who started off with more, it may be that they simply did not have enough time to do so and that if we had followed them for a longer period of time, they might have caught up eventually. Thus, understanding the dynamics of short- and longer-term changes and capturing these through different time lags is a fruitful avenue for future research. 
Such patterns may also emerge based on differences in perceptions and consequences of perceived job demands in addition to early levels of newcomer resources. Indeed, one tenet of COR theory is that gains in resources are particularly salient in the context of real or perceived resource loss. Work on expatriate adjustment by Firth, Chen, Kirkman, and Kim (2014) indicates that the nature of different job demands may matter and that examining their differences in terms of gain and loss cycles is an important next step in this line of research. Additionally, Crawford, LePine, and Rich (2010) found that demands do not always lead to negative outcomes. Thus, it is not clear if the findings of Firth et al. would be consistent with domestic newcomer samples or if additional nuances exist in the process of perceiving and acting upon demands and drawing upon resources during socialization. Consequently, potential future research opportunities exist to examine this further.

Our study was only able to focus on one of two interdependent socialization processes as outlined by Nicholson (1984), which include changes to the newcomer themselves in terms of their own adjustment (the focus of this study) and changes to the tasks or nature of the work performed by the newcomer (i.e., organizational changes). As such, we were able to observe relationships between resources and changes in newcomer adjustment indicators, however, outside of these initial resources, we were not able to observe what newcomer behaviors or other changes may have occurred which may have influenced the availability of resources or patterns of adjustment obtained. It is plausible that newcomers beginning their tenure with low resources find ways to craft their jobs such that demands are reduced (Tims, Bakker, \& Derks, 2012). In turn, these changes to the role itself may explain seemingly sudden increases in newcomers' perceptions of adjustment. Future work building on the current research might incorporate role and organizational changes that may influence the nature and trajectory of newcomer adjustment.

A related question is the extent to which contextual factors such as organizational socialization tactics influence newcomer perceptions of resource availability as noted by Saks and Ashforth (1997) 
and proactive newcomer tactics as found by Song, Liu, Shi, and Wang (2017). Ellis et al. (2015) positioned organizational tactics as an additional source of newcomer resources which would be considered by newcomers when taking inventory of their resource availability and considering the demands of their new work environment. Indeed, substantial prior research has established the helpful effects of structured approaches to newcomer socialization (Saks et al., 2007). This especially makes sense to examine further as Kim, Cable, and Kim (2005) found that tactics and employee proactivity moderated the relationship between tactics and person-organization fit perceptions for the South Korean new employee sample studied. The timing of these tactics may also be relevant, as one might imagine that a newcomer who is virtually connected with other newcomers or current employees prior to their start date, may enter on the first day with a higher level of perceived social acceptance. In our study, data were collected from employees within a single organization and in the same location. We assumed similarity in terms of socialization experiences directed by the organization, however without directly collecting data on tactics, we are unable to confirm that assumption. As such, we encourage future studies to incorporate organizational tactics as a source for newcomer resources.

\section{CONCLUSION}

This research sought to garner a greater understanding of the role of resources in explaining how newcomers adjust to their new work situation. Drawing on COR theory and utilizing data from a Fortune 500 technology company, we found evidence to support the notion that initial newcomer resources, especially personal resources, matter for newcomer adjustment. Moreover, differential patterns of adjustment were observed depending on the adjustment indicator examined (role clarity, feelings of acceptance, task mastery) and the associated newcomer resource. Further, we found partial evidence that early adjustment and rate of adjustment may influence manager ratings of adjustment. 
We encourage continued research investigating the nuanced role of newcomer resources and their impact on adjustment over time. 


\section{REFERENCES}

Allen, D. G., \& Shanock, L. R. 2013. Perceived organizational support and embeddedness as key mechanisms connecting socialization tactics to commitment and turnover among new employees. Journal of Organizational Behavior, 34: 350-369.

Allen, T. D., Eby, L. T., Chao, G. T., \& Bauer, T. N. 2017. Tracing the history and shaping the future of socialization and mentoring research. Journal of Applied Psychology, 102: 324-337.

Ashford, S. J., \& Black, J. S. 1996. Proactivity during organizational entry: The role of desire for control. Journal of Applied Psychology, 81: 199-214.

Ashforth, B. E. 2001. Role transitions in organizational life: An identity-based perspective. LEA Publishers.

Ashforth, B. E. 2012. The role of time in socialization dynamics. In C. R. Wanberg (Ed.), The Oxford handbook of organizational socialization, Vol. 22: 161-186. Oxford University Press.

Ashforth, B. E., Sluss, D. M., \& Saks, A. M. 2007. Socialization tactics, proactive behavior, and newcomer learning: Integrating socialization models. Journal of Vocational Behavior, 70: 447462.

Bakker, A. B., Tims, M., \& Derks, D. 2012. Proactive personality and job performance: The role of job crafting and work engagement. Human Relations, 65: 1359-1378.

Bateman, T. S., \& Crant, J. M. 1993. The proactive component of organizational behavior: A measure and correlates. Journal of Organizational Behavior, 14: 103-118.

Bauer, T. N., Bodner, T., Erdogan, B., Truxillo, D. M., \& Tucker, J. S. 2007. Newcomer adjustment during organizational socialization: A meta-analytic review of antecedents, outcomes, and methods. Journal of Applied Psychology, 92: 707-721.

Bauer, T. N., \& Erdogan, B. 2014. Delineating and reviewing the role of newcomer capital in 
organizational socialization. Annual Review of Organizational Psychology and Organizational Behavior, 1: 439-457.

Bauer, T. N., \& Green, S. G. 1998. Testing the combined effects of newcomer information seeking and managerial behavior on socialization. Journal of Applied Psychology, 83: 72-83.

Bauer, T. N., Morrison, E. W., \& Callister, R. R. 1998. Organizational socialization: A review and directions for future research. In G. R. Ferris (Ed.), Research in personnel and human resources management, Vol. 16: 149-214. JAI Press.

Berger, C. R., \& Calabrese, R. J. 1975. Some explorations in initial interaction and beyond: Toward a developmental theory of interpersonal communication. Human Communication Research, 1: 99112.

Boswell, W. R., Shipp, A. J., Payne, S. C., \& Culbertson, S. S. 2009. Changes in newcomer job satisfaction over time: Examining the pattern of honeymoons and hangovers. Journal of Applied Psychology, 94: 844-858.

Chan, D., \& Schmitt, N. 2000. Interindividual differences in intraindividual changes in proactivity during organizational entry: A latent growth modeling approach to understanding newcomer adaptation. Journal of Applied Psychology, 85: 190-210.

Chen, G., Ployhart, R. E., Thomas, H. C., Anderson, N., \& Bliese, P. D. 2011. The power of momentum: A new model of dynamic relationships between job satisfaction change and turnover intentions. Academy of Management Journal, 54: 159-181.

Cheung, G. W., \& Rensvold, R. B. 2002. Evaluating goodness-of-fit indexes for testing measurement invariance. Structural Equation Modeling, 9: 233-255.

Curran, P. J., Bauer, D. J., \& Willoughby, M. T. 2004. Testing main effects and interactions in latent curve analysis. Psychological Methods, 9: 220-237. 
Ellis, A. M., Bauer, T. N., Mansfield, L. R., Erdogan, B., Truxillo, D., \& Simon, L. 2015. Navigating uncharted waters: Newcomer socialization through the lens of stress theory. Journal of Management, 41: 203-235

Ellis, A. M., Nifadkar, S. S., Bauer, T. N., \& Erdogan, B. 2017. Newcomer adjustment: Examining the role of managers' perception of newcomer proactive behavior during organizational socialization. Journal of Applied Psychology, 102: 993-1001.

Enders, C. K. 2010. Applied missing data analysis. Guilford Press.

Fang, R., Duffy, M. K., \& Shaw, J. D. 2011. The organizational socialization process: Review and development of a social capital model. Journal of Management, 37: 127-152.

Feldman, M. S., \& March, J. G. 1981. Information in organizations as signal and symbol. Administrative Science Quarterly, 26: 171-186.

Fey, W. F. 1955. Acceptance by others and its relation to acceptance of self and others: A revaluation. The Journal of Abnormal and Social Psychology, 50: 274-276.

Firth, B. M., Chen, G., Kirkman, B. L., \& Kim, K. 2014. Newcomers abroad: Expatriate adaptation during early phases of international assignments. Academy of Management Journal, 57: 280-300.

George, J. M., \& Jones, G. R. 2000. The role of time in theory and theory building. Journal of Management, 26: 657-684.

Halbesleben, J. R. B., Neveu, J-P., Paustian-Underdahl, S. C., \& Westman, M. 2014. Getting to the "COR": Understanding the role of resources in Conservation of Resources Theory. Journal of Management, 40: 1334-1364.

Hobfoll, S. E. 1988. The ecology of stress. Hemisphere Publishing.

Hobfoll, S. E. 1989. Conservation of resources: A new approach at conceptualizing stress. American Psychologist, 44: 513-524. 
Hobfoll, S. E. 2001. The influence of culture, community, and the nested-self in the stress process: Advancing conservation of resources theory. Applied Psychology, 50: 337-421.

Hobfoll, S. E. 2002. Social and psychological resources and adaptation. Review of General Psychology, 6: 307-324.

Hobfoll, S. E. 2010. Conservation of resources theory: Its implications for stress, health, and resilience. In S. Folkman (Ed.), The Oxford Handbook of stress, health, and coping: 127-147. Oxford University Press.

Hu, L. T., \& Bentler, P. M. 1999. Cutoff criteria for fit indexes in covariance structure analysis: Conventional criteria versus new alternatives. Structural Equation Modeling: A Multidisciplinary Journal, 6: 1-55.

Jokisaari, M., \& Nurmi, J.-E. 2009. Change in newcomers' supervisor support and socialization outcomes after organizational entry. Academy of Management Journal, 52: 527-544.

Jokisaari, M., \& Nurmi, J.-E. 2012. Getting the right connections? The consequences and antecedents of social networks in newcomer socialization. In C. Wanberg (Ed.), The Oxford handbook of organizational socialization: 78-97. Oxford University Press.

Kammeyer-Mueller, J. D., \& Wanberg, C. 2003. Unwrapping the organizational entry process: Disentangling multiple antecedents and their pathways to adjustment. Journal of Applied Psychology, 88: 779-794.

Kammeyer-Mueller, J. D., Wanberg, C., Rubenstein, A., \& Song, Z. 2013. Support, undermining, and newcomer socialization: Fitting in during the first 90 days. Academy of Management Journal, 56: 1104-1124.

Kim, T-Y, K., Cable, D. C., \& Kim, S-P. 2005. Socialization tactics, employee proactivity, and person-organization fit. Journal of Applied Psychology, 90: 232-241. 
Lance, C. E., Meade, A. W., \& Williamson, G. M. 2000. We should measure change-and here's how. In G. M. Williamson, D. R. Shaffer, \& P. A. Parmelee (Eds.), Physical illness and depression in older adults: A handbook of theory, research, and practice: 201-235. Kluwer Academic/Plenum.

Li, N., Harris, B. T., Boswell, W. R., \& Xie, Z. 2011. The role of organizational insiders’ developmental feedback and proactive personality on newcomers' performance: An interactionist perspective. Journal of Applied Psychology, 96: 1317-1327.

Lombardo, M. M., \& Eichinger, R. W. 2000. High potentials as high learners. Human Resource Management, 39: 321-329.

McArdle, J. J., \& Nesselroade, J. R. 2014. Longitudinal data analysis using structural equation models. APA.

McDonald, R.P. 1989. An index of goodness-of-fit based on noncentrality. Journal of Classification, 6: 97-103.

Meade, A. W., Johnson, E. C., \& Braddy, P. W. 2008. Power and sensitivity of alternative fit indices in tests of measurement invariance. Journal of Applied Psychology, 93: 568-592.

Morrison, E. W. 2002. Newcomers' relationships: The role of social network ties during socialization. Academy of Management Journal, 45: 1149-1160.

Newman, D. A. 2003. Longitudinal modeling with randomly and systematically missing data: A simulation of ad hoc, maximum likelihood, and multiple imputation techniques. Organizational Research Methods, 6: 328-362.

Newsom, J. 2015. Longitudinal structural equation modeling: A comprehensive introduction. Routledge.

Nicholson, N. 1984. A theory of work role transitions. Administrative Science Quarterly, 29: 172-191.

Nifadkar, S. S., \& Bauer, T. N. 2016. Breach of belongingness: Newcomer relationship conflict, 
information, and task-related outcomes during organizational socialization. Journal of Applied Psychology, 101: 1-13.

Nifadkar, S. S. 2020. Filling in the "blank slate": Examining newcomers' schemas of supervisors during organizational socialization. Journal of Management, 46: 666-693

Reichers, A. E. 1987. An interactionist perspective on newcomer socialization rates. Academy of Management Review, 12: 278-287.

Reio, T. G., \& Callahan, J. L. 2004. Affect, curiosity, and socialization-related learning: A path analysis of antecedents to job performance. Journal of Business and Psychology, 19: 3-22.

Rizzo, J., House, R. J., \& Lirtzman, S. I. 1970. Role conflict and role ambiguity in complex organizations. Administrative Science Quarterly, 15: 150-163.

Rollag, K. 2004. The impact of relative tenure on newcomer socialization dynamics. Journal of Organizational Behavior, 25: 853-872.

Rosseel, Y. 2012. Lavaan: An R package for structural equation modeling and more. Journal of Statistical Software, 48: 1-36.

Saks, A.M. and Ashforth, B.E., 1997. Organizational socialization: Making sense of the past and present as a prologue for the future. Journal of vocational Behavior, 51: 234-279.

Saks, A. M., \& Ashforth, B. E. 2000. The role of dispositions, entry stressors, and behavioral plasticity theory in predicting newcomers' adjustment to work. Journal of Organizational Behavior, 21: 43-62.

Saks, A. M., \& Gruman, J. A. 2011. Organizational socialization and positive organizational behavior: Implications for theory, research, and practice. Canadian Journal of Administrative Sciences, 28: 14-26.

Saks, A. M., \& Gruman, J. A. 2012. Getting newcomers on board: A review of socialization practices and introduction to socialization resources theory. In C. Wanberg (Ed.), The Oxford handbook of 
organizational socialization: 27-55. Oxford University Press.

Saks, A. M., Uggerslev, K. L., \& Fassina, N. E. 2007. Socialization tactics and newcomer adjustment: A meta-analytic review and test of a model. Journal of Vocational Behavior, 70: 413-446.

Scheier, M. F., Carver, C. S. \& Bridges, M. W. 1985. Life orientation test. Lawrence Erlbaum Assoc. Simon, L. S., Bauer, T. N., Erdogan, B., \& Shepherd, W. 2019. Built to last: Interactive effects of perceived overqualification and proactive personality on new employee adjustment. Personnel Psychology, 72: 213-240.

Song, Y., Liu, Y., Shi, J., \& Wang, M. 2017. Use of proactive socialization tactics and socialization outcomes: A latent growth modeling approach to understanding newcomer socialization. Academy of Management Discoveries, 3: 42-63.

Stibitz, S. (2015). How to get a new employee up to speed. Harvard Business Review: 2-5.

Tims, M., Bakker, A. B., \& Derks, D. 2012. The development and validation of the Job Crafting Scale. Journal of Vocational Behavior, 80: 173-186.

U. S. Bureau of Labor Statistics. 2019. Retrieved at https://www.bls.gov/news.release/pdf/nlsoy.pdf

Vandenberg, R. J., \& Lance, C. E. 2000. A review and synthesis of the measurement invariance literature: Suggestions, practices, and recommendations for organizational research. Organizational Research Methods, 3: 4-70.

Wanberg, C. R. 2012. The Oxford handbook of organizational socialization. Oxford University Press. Xanthopoulou, D., Bakker, A. B., Demerouti, E., \& Schaufeli, W. B. 2009. Reciprocal relationships between job resources, personal resources, and work engagement. Journal of Vocational Behavior, 74: 235-244. 
Table 1

Descriptive Statistics and Between- and Within-Person Correlations for Study Variables

\begin{tabular}{|c|c|c|c|c|c|c|c|c|c|c|c|c|c|c|c|}
\hline Variables & $\mathrm{M}$ & SD & 1. & 2. & 3. & 4. & 5. & 6. & 7. & 8. & 9. & 10. & 11. & 12. & 13. \\
\hline 1. Proactive Personality T0 & 4.17 & .45 & - & & & & & & & & & & & & \\
\hline 2. Optimistic Personality T0 & 4.12 & .55 & $.50 * *$ & - & & & & & & & & & & & \\
\hline 3. Organizational Knowledge T0 & .05 & .21 & .00 & .03 & - & & & & & & & & & & \\
\hline 4. Previous Work Experience T0 & .32 & .47 & -.02 & .00 & $-.08 *$ & - & & & & & & & & & \\
\hline 5. Work Station Ready T0 & .88 & .33 & .05 & $.07 *$ & .06 & -.07 & - & & & & & & & & \\
\hline 6. Computer Ready T0 & .96 & .21 & .04 & .00 & .05 & -.04 & $.09 *$ & - & & & & & & & \\
\hline 7. Insider Relationships T0 & .37 & .48 & .07 & .04 & .04 & .02 & -.05 & -.03 & - & & & & & & \\
\hline 8. Newcomer Job Level T0 & 3.62 & 1.31 & .06 & -.01 & $-.14 * *$ & $-.35 * *$ & .03 & $.08^{*}$ & .00 & - & & & & & \\
\hline 9. Met Manager First Day T0 & .74 & .44 & .04 & .07 & $.08 *$ & -.07 & $.35 * *$ & .07 & -.01 & $.10 * *$ & - & & & & \\
\hline 10. Role Clarity T1-T4 average & 3.96 & .50 & .21 & $.30 * *$ & $.16^{* *}$ & -.09 & .05 & .03 & .03 & -.01 & .06 & - & $.37 * *$ & $.34 * *$ & \\
\hline 11. Task Mastery T1-T4 average & 4.09 & .52 & $.46^{* *}$ & $.40 * *$ & $.20 * *$ & $-.11 *$ & .06 & .03 & -.05 & .04 & $.16^{* *}$ & $.63 * *$ & - & $.26 * *$ & \\
\hline 12. Acceptance T1-T4 average & 4.19 & .45 & $.35 * *$ & $.31 * *$ & .04 & .07 & -.04 & -.03 & .04 & -.06 & .10 & $.61 * *$ & $.48 * *$ & - & \\
\hline 13. Manager-rated Adjustment T4 & 4.57 & .52 & .00 & .05 & $.09 *$ & -.01 & -.02 & .03 & .04 & .00 & $-.11 *$ & $.11 *$ & $.14 * *$ & $.12 *$ & - \\
\hline 14. Manager-rated Adjustment T5 & 4.68 & .48 & .00 & -.01 & .01 & .02 & -.04 & -.04 & .06 & $-.15 * *$ & -.02 & .01 & -.01 & .08 & $.61 * *$ \\
\hline
\end{tabular}

Note. $N=418-985$. Between-person correlations with pairwise deletion are presented below the diagonal, and within-person correlations with pairwise deletion for the time-varying adjustment variables are presented above the diagonal. Organizational knowledge: $1=$ prior temporary worker or contractor, $0=$ not prior temporary worker or contractor. Previous work experience: $1=$ first job, $0=$ not first job. Work station ready: 1 $=$ yes, $0=$ no. Computer ready: $1=$ yes, $0=$ no. Insider relationships: $1=$ yes friends or family work at company, $0=$ no. Newcomer job level: $1=$ job level 1, $7=$ job level 7. Met manager first day: $1=$ yes, $0=$ no. $\mathrm{T} 0=$ first day on the job, $\mathrm{T} 1=1$ month, $\mathrm{T} 2=3$ months, $\mathrm{T} 3=6$ months, $\mathrm{T} 4=9$ months, and T5 $=12$ months post-entry. ${ }^{*} p<.05 ; * * p<.01$. 


\section{Table 2}

Hypothesis 1 and Research Question 1: Conditional Latent Growth Models with Resources as Time-Invariant Predictors

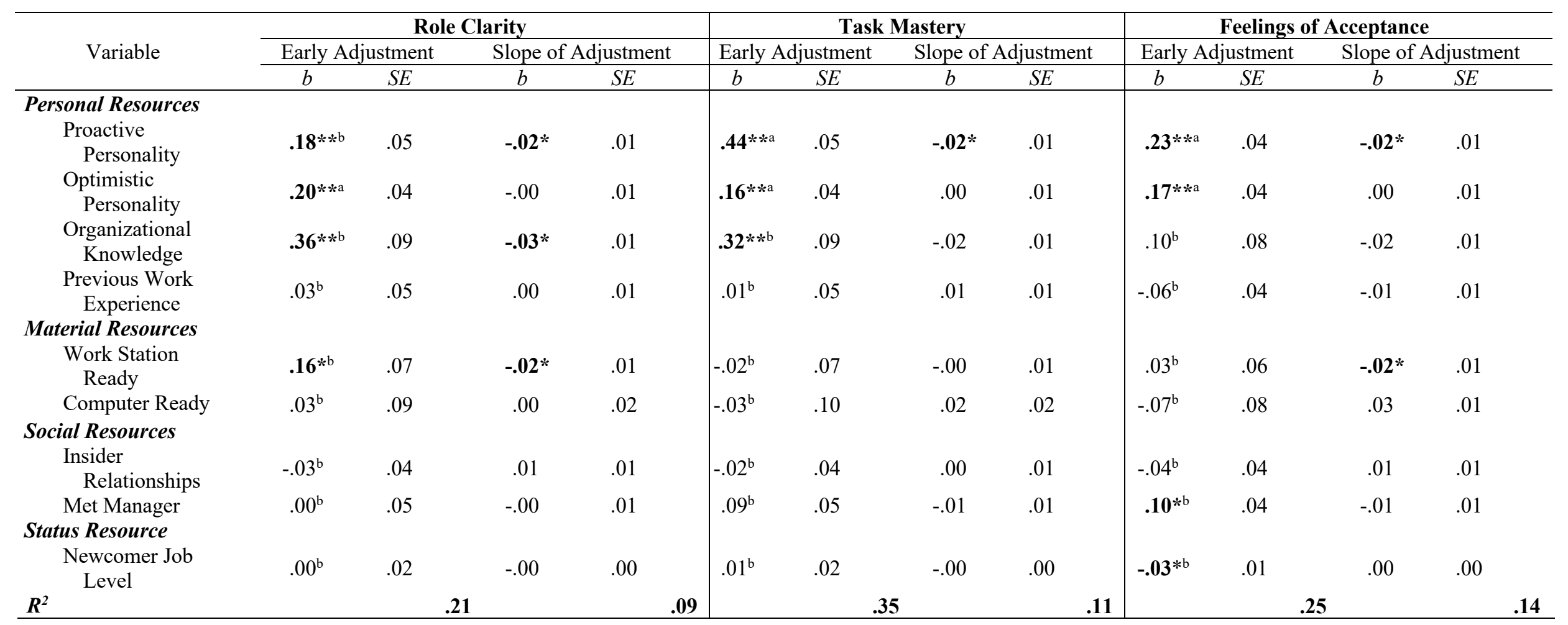

Note. $N=985$. Solid lines designate separate models. Reported coefficients are unstandardized. Organizational knowledge: $1=$ prior temporary worker or contractor, $0=$ not prior temporary worker or contractor. Previous work experience: $0=$ first job, $1=$ not first job. Work station ready: $0=$ no, $1=$ yes.

Computer ready: $0=$ no, $1=$ yes. Insider relationships: $0=$ no friends or family work at company, $1=$ friends or family work at company. Newcomer job level: $1=$ job level 1, $7=$ job level 7. Met manager first day: $0=$ no, $1=$ yes. ${ }^{a}$ Intercept difference was significant $(p<.05)$ at 9 months ${ }^{b}$ Intercept difference was not significant $(p>.10)$ at 9 months

$* p<.05 ; * *<.01$. 
Table 3

Hypotheses 2 and 3: Conditional Latent Growth Models with Manager Ratings of Adjustment as Time-Invariant Outcome

\begin{tabular}{|c|c|c|c|c|c|c|}
\hline \multirow[b]{2}{*}{ Outcome } & \multicolumn{3}{|c|}{$\begin{array}{l}\text { Manager Ratings of Adjustment } \\
9 \text { Months Post-Entry }\end{array}$} & \multicolumn{3}{|c|}{$\begin{array}{c}\text { Manager Ratings of Adjustment } \\
12 \text { Months Post-Entry }\end{array}$} \\
\hline & $b$ & $S E$ & $R^{2}$ & $b$ & $S E$ & $R^{2}$ \\
\hline Early Role Clarity (1 month) & $.17 * *$ & .06 & & .10 & .06 & \\
\hline Slope of Role Clarity (1-9 months) & $2.54 *$ & .99 & .06 & $2.32 *$ & 1.05 & .04 \\
\hline Early Task Mastery (1 month) & $.22 * *$ & .06 & & .10 & .06 & \\
\hline Slope of Task Mastery (1-9 months) & 3.47 & 2.01 & .08 & 2.96 & 2.03 & .04 \\
\hline Early Feelings of Acceptance (1 month) & $.15 *$ & .07 & & .12 & .07 & \\
\hline Slope of Feelings of Acceptance (1-9 months) & $3.37 *$ & 1.38 & .07 & 1.37 & 1.30 & .02 \\
\hline
\end{tabular}

Note. $N=955-956$. Reported coefficient estimates are unstandardized. Significant coefficients are in bold font.

$* p<.05 ; * * p<.01$. 
Figure 1

Overview of Hypothesized Initial Newcomer Resources and Newcomer Adjustment Over Time

Newcomer Resources

\begin{tabular}{|c}
\hline Material Resources \\
(T0) \\
Work Station \\
Ready (Day 1) \\
Computer \\
Ready (Day 1)
\end{tabular}

\section{Personal Resources} (T0)

Proactive

Personality

Optimistic

Personality

Organizational

Knowledge

Previous Work

Experience

\section{Social Resources (T0)}

Insider

Relationships

Met Manager

(Day 1)

Status Resources

Org(T0)

Ento6 Leve
Newcomer-rated Adjustment Manager-rated Newcomer Adjustment
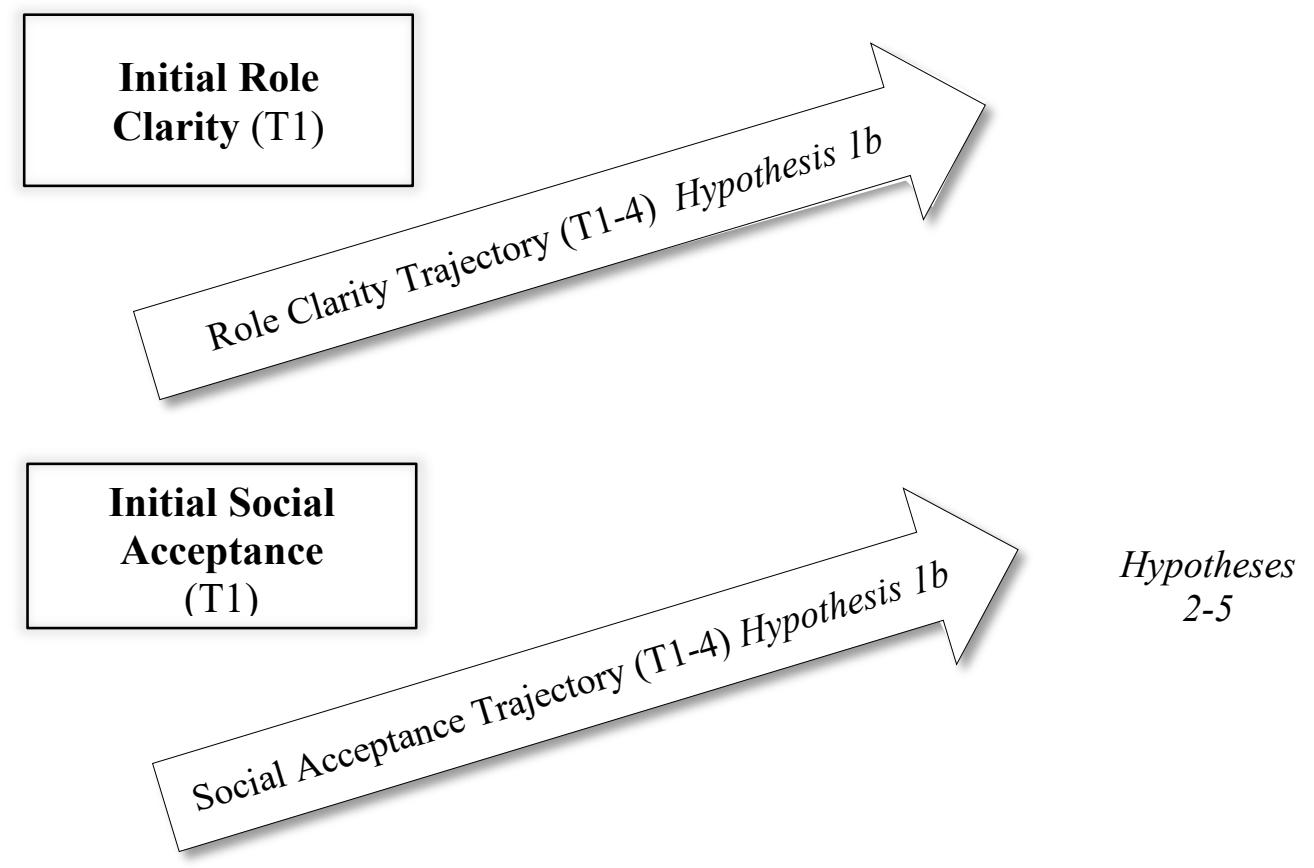

Question 1:

Which

resources

matter most?

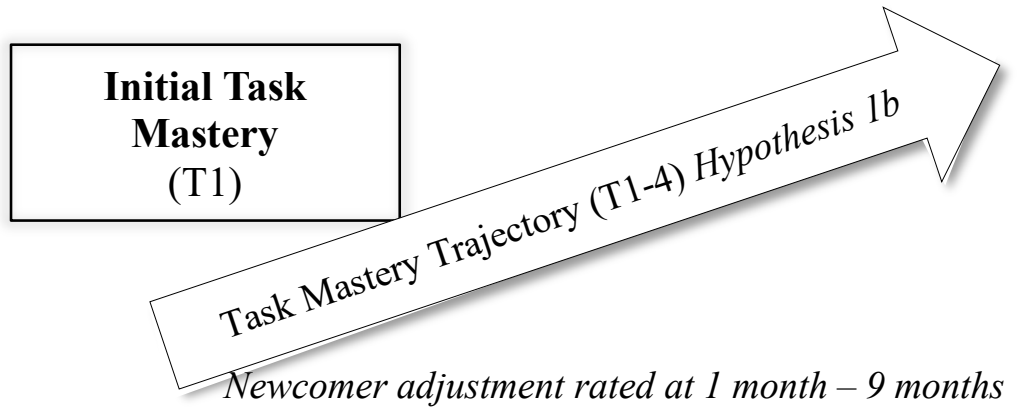




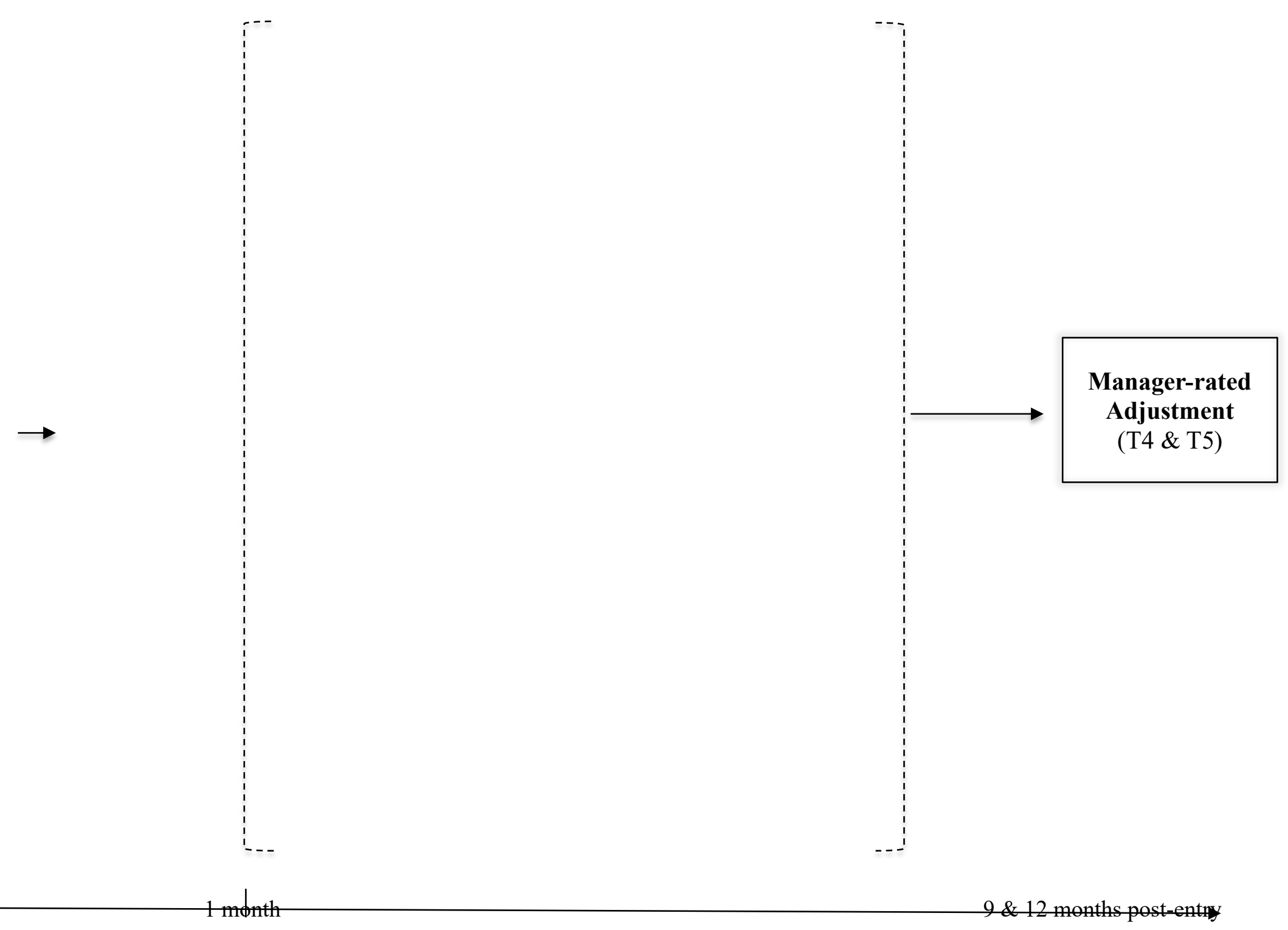


Figure 2

Findings for Specific Newcomer Day 1 Resources and Adjustment Patterns Over Time

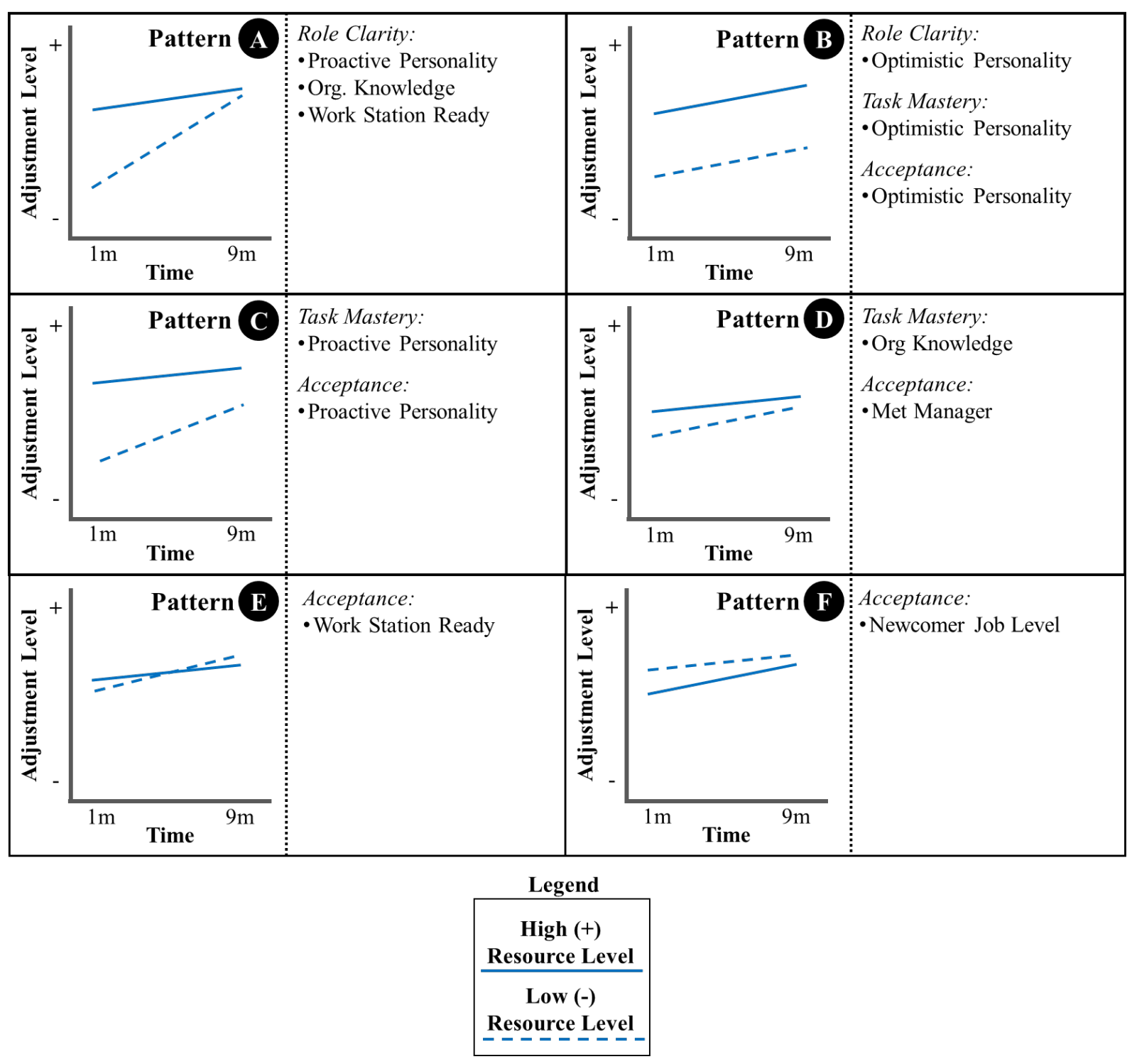




\section{APPENDIX A}

\section{Response Rates and Missing Data}

Given the longitudinal design, we observed some missing responses for the 985 employees who participated in the study. The company provided data and responses for those employees who were still employees 12 months post-hire. With respect to our measure of organizational knowledge (i.e., having previously worked for organization), we obtained records for all 985 employees who participated in at least one survey. Newcomer self-report survey response rates were as follows across post-hire time points: $82 \%(n=809)$ at day $1(\mathrm{~T} 0), 75 \%(n=734)$ at 1 month (T1), 75\% $(n=740)$ at 3 months $(\mathrm{T} 2), 65 \%(n=639)$ at 6 months (T3), and 58\% $(n=$ $572)$ at 9 months (T4). Finally, 54\% $(n=532)$ of newcomers at 9 months (T4) and 55\% $(n=$ 544) of newcomers at 12 months (T5) received manager ratings of their level of adjustment.

We explored whether there were any patterns of systematic missing data. Specifically, to examine whether participants who provided complete data across all self-report surveys (from T0-T4) differed from those who did not, we ran several analyses. First, we used logistic regression to test whether differences existed with respect to $\mathrm{T} 0$ variables between those who provided complete data across self-report survey waves and those who provided partially complete data. We did not find any significant differences between those who had complete versus partially complete data. Second, due to the repeated-measures nature of the adjustment indicators, using latent growth models, we examined whether a dichotomous (complete data versus partially complete data) time-invariant predictor variable was associated with early adjustment (intercept) and adjustment slope for each of the adjustment indicators. We did not find any significant associations, leading us to conclude that the data were missing at random. While not definitive, these analyses and results suggest that missing data was not a systematic threat to the validity of our findings or a viable alternative explanation for our findings.

Given that evidence indicated that the data were missing at random, data analyses were performed using estimated using full information maximum likelihood (FIML). FIML provides adjusted parameter estimates and standard errors to account for inferential uncertainty due to missing data, and it requires the missing at random (MAR) assumption as opposed to the more stringent missing completely at random (MCAR) assumption. The FIML estimator is preferable to traditional approaches to dealing with missing data, such as listwise deletion and arithmetic mean imputation, particularly when using longitudinal designs (Enders, 2010; Newman, 2003). 


\section{APPENDIX B}

Descriptive statistics for adjustment variables at each time period

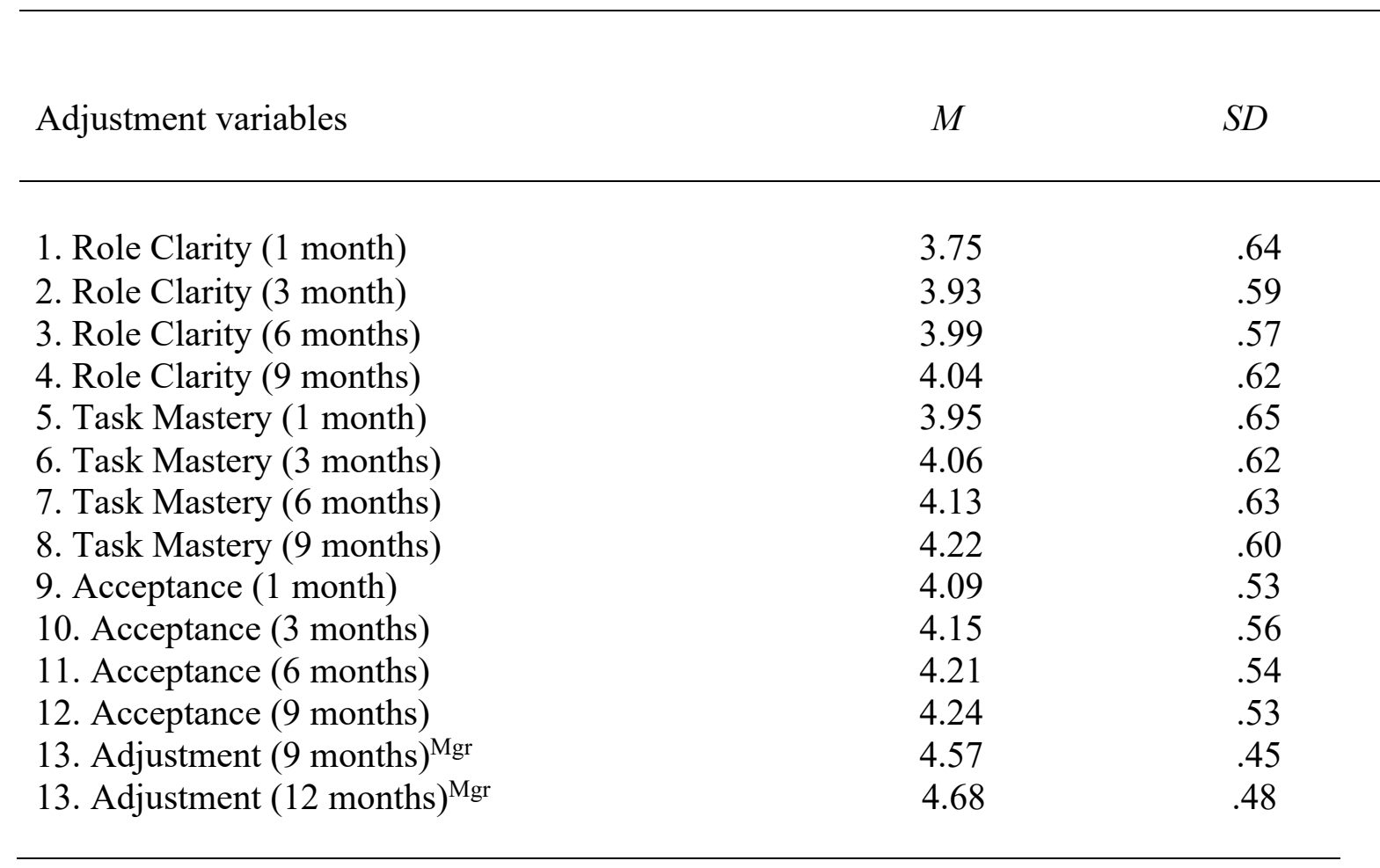

Note. The response scales for each of these ranged from a low of 1 to a high of 5. Specific adjustment variables rated by new employees at four time points. ${ }^{\text {Mgr }}$ indicates adjustment at 9 and 12 months rated by the new employee's manager. 


\section{APPENDIX C: Measurement Invariance and Analyses}

To interpret LGMs in a meaningful manner, evidence is needed that, over time, indicates consistent measurement structure and measurement invariance exists (Lance, Meade, \& Williamson, 2000; Vandenberg \& Lance, 2000). To do so, we followed a multistep process involving nested model comparisons for each adjustment measure. Models were compared using likelihood ratio tests (LRTs), change in comparative fit index ( $\triangle \mathrm{CFI})$, and change in McDonald's (1989) noncentrality index ( $\Delta \mathrm{Mc}$ ) (Cheung \& Rensvold, 2002; Meade, Johnson, \& Braddy, 2008). Given that LRTs are more sensitive in larger samples such as the sample in this study, model comparison decisions were made based on $\Delta \mathrm{CFI}$ and $\Delta \mathrm{Mc}$. For $\Delta \mathrm{CFI}$, a value of .002 or less has been shown to be a suitable indicator of similarity in model, and for $\Delta \mathrm{Mc}$, given that the adjustment measures had either three or five items, a value of .0065 or less was used as the threshold (Meade, Johnson, \& Braddy, 2008).

First, we evaluated configural invariance by estimating the measurement model of a given construct across the four measurement occasions and allowed the error variances (i.e., uniquenesses) for the same item to covary across measurement occasions. Second, we estimated scalar invariance by taking the configural model and constraining the factor loadings for the same item to be equal across measurement occasions. We then compared the fit of the configural and scalar invariance models; if fit did not notably worsen when constraints were imposed, the more parsimonious model with the added constraints was retained. Third, we evaluated metric invariance by taking the scalar model and constraining the intercepts for the same item to be equal across measurement occasions. Fourth, we evaluated uniqueness invariance by taking the metric model and constraining the uniquenesses of the same item to be equal across measurement occasions. Finally, if full metric or uniqueness invariance was not met in steps three or four, partial metric or uniqueness invariance constraints were imposed and additional nested model comparisons were evaluated. Detailed information regarding measurement invariance nested model comparisons is shown in Appendix C, Table 1C, and a summary is provided below.

Role clarity showed evidence of configural and metric invariance, and partial scalar and uniqueness invariance. Specifically, the final model (Model 6) included equal factor loadings, and all same-item intercepts were constrained to be equal, except: the second item intercepts at $\mathrm{T} 1$ and T4 were freely estimated, but the T2 and T3 item intercepts were constrained to be equal; the third item intercepts at T1 and T2 were constrained to be equal, and the third item intercepts at T3 and T4 were constrained to be equal; the fifth item intercept at T1 was freely estimated. Further, all same-item uniquenesses were constrained to be equal, except the fourth item variance at $\mathrm{T} 1$ was freely estimated.

Task mastery also showed evidence of configural and metric invariance, and partial scalar and uniqueness invariance. Specifically, the final model (Model 6) included equal factor loadings, and all same-item intercepts were constrained to be equal, except: the second item intercept at T3 was freely estimated, and the third item intercepts at T1 and T4 were freely estimated; further, all same-item uniquenesses were constrained to be equal, except: the first item variance at $\mathrm{T} 1$ was freely estimated; the second item variance at $\mathrm{T} 1$ was freely estimated; and the third item variances at T1 and T4 were freely estimated.

Feelings of acceptance showed evidence of configural, metric, and scalar invariance, and partial uniqueness invariance. Specifically, the final model (Model 5) included equal factor loadings and equal same-item intercepts, and all same-item uniquenesses were constrained to be equal, except the first item variance at T4 was freely estimated. 
APPENDIX C, Table 1C. Measurement Invariance: Role Clarity, Task Mastery, and Feelings of Acceptance

\begin{tabular}{|c|c|c|c|c|c|c|c|c|c|c|c|}
\hline & $\begin{array}{c}\text { Model } \\
\text { Comparison }\end{array}$ & LRT & $\chi^{2}$ & $d f$ & CFI & $\Delta \mathrm{CFI}$ & Mc & $\Delta \mathrm{Mc}$ & TLI & RMSEA & SRMR \\
\hline \multicolumn{12}{|l|}{ Role Clarity } \\
\hline 1. Factor structures & & & 201.198 & 134 & .990 & & .965 & & .986 & .023 & .030 \\
\hline 2. Factor loadings equal & $1 \& 2$ & 13.321 & 214.518 & 146 & .990 & .000 & .964 & -.001 & .987 & .022 & .034 \\
\hline 3. Item intercepts equal & $2 \& 3$ & $52.564 * *$ & 267.082 & 158 & .984 & -.006 & .943 & -.021 & .981 & .027 & .035 \\
\hline 4. Item uniquenesses equal & $3 \& 4$ & $32.779 * *$ & 299.861 & 173 & .981 & -.003 & .934 & -.009 & .980 & .028 & .037 \\
\hline $\begin{array}{l}\text { 5. Item intercepts partially } \\
\text { equivalent }\end{array}$ & $2 \& 5$ & $18.616^{*}$ & 233.135 & 154 & .988 & -.002 & .958 & -.006 & .986 & .023 & .033 \\
\hline $\begin{array}{l}\text { 6. Item intercepts and uniquenesses } \\
\text { partially equivalent }\end{array}$ & $5 \& 6$ & 19.546 & 252.681 & 168 & .988 & .000 & .956 & -.002 & .986 & .023 & .034 \\
\hline \multicolumn{12}{|l|}{ Task Mastery } \\
\hline 1. Factor structures & & & 59.639 & 30 & .994 & & .984 & & .986 & .033 & .038 \\
\hline 2. Factor loadings equal & $1 \& 2$ & 3.845 & 63.484 & 36 & .994 & .000 & .985 & .001 & .990 & .029 & .040 \\
\hline 3. Item intercepts equal & $2 \& 3$ & $156.200 * *$ & 219.687 & 42 & .963 & -.031 & .909 & -.076 & .990 & .067 & .040 \\
\hline 4. Item uniquenesses equal & $3 \& 4$ & $162.390 * *$ & 382.077 & 51 & .931 & -.032 & .837 & -.072 & .911 & .084 & .067 \\
\hline $\begin{array}{l}\text { 5. Item intercepts partially } \\
\text { equivalent }\end{array}$ & $2 \& 5$ & $9.720^{*}$ & 73.204 & 39 & .993 & -.001 & .982 & -.003 & .988 & .031 & .039 \\
\hline $\begin{array}{l}\text { 6. Item intercepts and uniquenesses } \\
\text { partially equivalent }\end{array}$ & $5 \& 6$ & 7.101 & 80.305 & 44 & .992 & -.001 & .981 & -.001 & .989 & .030 & .040 \\
\hline \multicolumn{12}{|l|}{ Feelings of Acceptance } \\
\hline 1. Factor structures & & & 26.089 & 30 & 1.000 & & 1.002 & & 1.002 & .000 & .017 \\
\hline 2. Factor loadings equal & $1 \& 2$ & 10.461 & 36.550 & 36 & 1.000 & .000 & 1.000 & -.002 & 1.000 & .004 & .023 \\
\hline 3. Item intercepts equal & $2 \& 3$ & 4.184 & 40.734 & 42 & 1.000 & .000 & 1.001 & .001 & 1.000 & .000 & .024 \\
\hline 4. Item uniquenesses equal & $3 \& 4$ & $23.687 * *$ & 64.421 & 51 & .997 & -.003 & .993 & -.008 & .996 & .017 & .028 \\
\hline $\begin{array}{l}\text { 5. Item intercepts equal and } \\
\text { uniquenesses partially equivalent }\end{array}$ & $3 \& 5$ & 13.073 & 53.807 & 50 & .999 & -.001 & .998 & -.003 & .999 & .009 & .026 \\
\hline
\end{tabular}

Note. $N=930-933$. LRT $=$ likelihood ratio test in which value represents difference in $\chi^{2}$ between nested models. For role clarity Model 5, all same-item intercepts were constrained to be equal, except: the second item intercepts at T1 and T4 were freely estimated, but the T2 and T3 item intercepts were constrained to be equal; the third item intercepts at T1 and T2 were constrained to be equal, and the third item intercepts at T3 and T4 were constrained to be equal; the fifth item intercept at T1 was freely estimated. For role clarity Model 6, all same-item uniquenesses (i.e., residual variances) were constrained to be equal, except the fourth item uniqueness at T1 was freely estimated. For task mastery Model 5, all same-item intercepts were constrained to be equal, except: the second item intercept at T3 was freely estimated, and the third item intercepts at T1 and T4 were freely estimated. For task mastery Model 6, all same-item uniquenesses were constrained to be equal, except: the first item uniqueness at T1 was freely estimated; the second item uniqueness at T1 was freely estimated; and the third item uniquenesses at T1 and T4 were freely estimated. For feelings of acceptance Model 5, all same-item variances were constrained to be equal, except the first item uniqueness at $\mathrm{T} 4$ was freely estimated.

$* p<.05 ; * * p<.01$ 


\section{APPENDIX D}

\section{Second-Order Unconditional Latent Growth Model Building}

When building unconditional latent growth models (LGMs) for role clarity, task mastery, and feelings of acceptance, we compared the following models to understand the functional form of change over time: (a) linear, (b) quadratic, and (c) cubic. For each linear model, we included an intercept factor and a linear slope factor, and set the linear slope factor loadings to $0,2,5$, and 8 (i.e., 1 month, 3 months, 6 months, 9 months), estimated the mean and variance of the linear slope factor, and estimated the covariance between the intercept and linear slope factors. Third, for each quadratic model, we adapted the linear model by adding a quadratic slope factor, set the quadratic slope factor loadings to $0,4,25$, and 64 , estimated the mean and variance of the quadratic slope factor, and estimated the covariances between all of the latent intercept and slope factors. Finally, for each cubic model, we adapted the quadratic model by adding a cubic slope factor, set the cubic slope factor loadings to $0,8,125$, and 512, estimated the mean and variance of the cubic slope factor, and estimated the covariances between all of the latent intercept and slope factors.

To determine which functional form best fit the data, the likelihood ratio test (LRT) and model fit indices were used to compare nested models. A detailed account of the model comparisons is shown in Appendix D, Table 1D. A linear functional form showed good fit to each adjustment indicator's unconditional LGM, and adding a quadratic factor did not incrementally improve the fit for role clarity or task mastery. For acceptance, a quadratic factor did improve model fit as evidenced by a significant LRT; however, for reasons of consistency and parsimony, we retained the linear unconditional LGM for acceptance as well. Models specified with a cubic factor were all non-positive definite, and the results were not reported. The three final linear unconditional LGMs each showed adequate fit to the data by conventional standards (Hu \& Bentler, 1999): role clarity $\left(\chi^{2}=256.42, d f=169, \mathrm{CFI}=.99\right.$, TLI $=.99$, RMSEA $=.02$, RMSEA 90\% CI[.02, .03], SRMR $=.04)$, task mastery $\left(\chi^{2}=82.898, d f=45\right.$, CFI $=.99, \mathrm{TLI}=.99, \mathrm{RMSEA}=.03, \mathrm{RMSEA} 90 \% \mathrm{CI}[.02, .04], \mathrm{SRMR}=.04)$, and acceptance $\left(\chi^{2}=\right.$ $70.656, d f=51, \mathrm{CFI}=1.00, \mathrm{TLI}=.99, \mathrm{RMSEA}=.02$, RMSEA 90\% CI[.01, .03], $\mathrm{SRMR}=.06)$. For each model, we examined the adjustment trajectories to determine whether the average trajectories were significantly different from zero and whether there was significant betweenperson variability in the trajectories. The means of the slope factors (which represent trajectories) were all positive and significant (role clarity: $\mu=.262, p<.001$; task mastery: $\mu=.272, p<$ .001 ; acceptance: $\mu=.271, p<.001$ ), indicating that in general newcomers' adjustment improved over their first 9 months. In addition, there was evidence of significant between-person variability in trajectories (role clarity: $\sigma=.002, p<.001$; task mastery: $\sigma=.001, p<.05$; acceptance: $\sigma=.001, p<.01)$, indicating the likely existence of time-invariant predictors (between-person moderators). Regarding the intercept factors, the means and variances were all significant (role clarity: $\mu=2.278, p<.001, \sigma=.185, p<.001$; task mastery: $\mu=2.570, p<$ $.001, \sigma=.211, p<.001$; acceptance: $\mu=2.556, p<.001, \sigma=.143, p<.001)$. Finally, the covariance between the intercept and slope factors for role clarity was significant and negative, and the same covariances for task mastery and acceptance were nonsignificant (role clarity: $\psi=$ $.008, p<.001$; task mastery: $\psi=-.004, p=.06$; acceptance: $\psi=-.003, p=.08$ ). 
APPENDIX D, Table 1D. Second-Order Unconditional Latent Growth Model Building: Role Clarity, Task Mastery, and Feelings of Acceptance

\begin{tabular}{|c|c|c|c|c|c|c|c|}
\hline & $\chi^{2}$ & $d f$ & LRT & CFI & TLI & RMSEA & SRMR \\
\hline \multicolumn{8}{|l|}{ Role Clarity } \\
\hline Linear & 256.415 & 169 & & .987 & .986 & .024 & .036 \\
\hline Quadratic & 252.681 & 165 & 3.734 & .987 & .985 & .024 & .034 \\
\hline Cubic $^{\mathrm{a}}$ & -- & -- & -- & -- & -- & -- & -- \\
\hline \multicolumn{8}{|l|}{ Task Mastery } \\
\hline Linear & 82.898 & 45 & & .992 & .988 & .030 & .042 \\
\hline Quadratic & 80.305 & 41 & 2.593 & .992 & .987 & .032 & .040 \\
\hline Cubic $^{\mathrm{a}}$ & -- & -- & -- & -- & -- & -- & -- \\
\hline \multicolumn{8}{|c|}{ Feelings of Acceptance } \\
\hline Linear & 70.656 & 51 & & .995 & .994 & .020 & .037 \\
\hline Quadratic & 53.807 & 47 & $16.849 * *$ & .998 & .998 & .012 & .026 \\
\hline Cubic $^{\mathrm{a}}$ & -- & -- & -- & -- & -- & -- & -- \\
\hline
\end{tabular}

Notes. $N=930-933$. LRT $=$ likelihood ratio test in which value represents difference in $\chi^{2}$ between nested models.

${ }^{a}$ Model was not positive definite, and results are not reported.

$* p<.05 * * p<.01$ 


\section{APPENDIX E}

\section{Post-Hoc Analyses for Newcomer Resources and Patterns of Adjustment}

Based on the results of the conditional LGMs used for Hypothesis 1, we identified whether a given resource variable was associated with early levels of an adjustment variable (at 1 month) and, if so, in what direction; we refer to this as Characteristic 1 (C1). Because conditional LGMs with time-invariant predictor variables can be thought of in terms of cross-level interactions, a significant association between a time-invariant resource variable and the latent intercept factor (i.e., early levels of adjustment) indicates an intercept difference exists based on values of the resource variable. In this context, a positive intercept difference indicates that higher levels of a resource are associated with higher levels of early adjustment, whereas a negative intercept difference indicates that higher levels of a resource are associated with lower levels of early adjustment.

Second, based on the results of the conditional LGMs used for Hypothesis 1 (which were the same conditional LGMs used to test Hypothesis 1), we identified whether a given resource variable was associated with rate of adjustment (from 1 month to 9 months) and, if so, in what direction; we refer to this as Characteristic 2 (C2). A significant association between a timeinvariant resource variable and the latent slope factor indicates that differences in rate of adjustment exist based on values of the resource variable. In this context, a positive slope difference indicates that higher levels of a resource are associated with faster rates of adjustment, whereas a negative slope difference indicates that higher levels of a resource are associated with slower rates of adjustment.

Third, we identified whether a given resource variable was associated with later levels of an adjustment variable (at 9 months) and, if so, in what direction; we refer to this as Characteristic 3 (C3). To determine whether differences in adjustment existed at 9 months based on values of a given resource variable, we shifted the latent intercept factor from 1 month in the original conditional LGMs to 9 months. Specifically, we set the linear slope factor loadings to -8 , $-6,-3$, and 0 (1 month, 3 months, 6 months, 9 months).

The results of the statistical tests for these three characteristics are shown in Table 2. Using these tests, we identified six qualitatively different adjustment patterns which we refer to as Patterns A-F, which we depict visually in Figure 2 and which we describe narratively. For Pattern A, newcomers with higher levels of a resource had higher early levels of adjustment (at 1 month) but subsequently adjusted at a slower rate than those who had lower levels of the resource; by 9 months, those with higher levels of the resource had similar levels of later adjustment when compared to those with lower levels of the resource. The personal resources of proactive personality $(\mathrm{C} 1: b=.18, p<.001 ; \mathrm{C} 2: b=-.02, p<.05 ; \mathrm{C} 3: b=.03, p=.547)$ and organizational knowledge $(\mathrm{C} 1: b=.36, p<.001 ; \mathrm{C} 2: b=-.03, p<.05 ; \mathrm{C} 3: b=.13, p=.166)$ and the material resource of having a work station ready on the first day $(\mathrm{C} 1: b=.16, p<.05 ; \mathrm{C} 2: b$ $=-.02, p<.05 ; \mathrm{C} 3: b=-.01, p=.900)$ showed this adjustment pattern in relation to role clarity.

For Pattern B, newcomers with higher levels of a resource had higher early levels of adjustment (at 1 month) and subsequently adjusted at a rate that was similar to those who had lower levels of the resource; by 9 months, those with higher levels of the resource continued to 
have higher levels of adjustment. The personal resource of optimistic personality showed this adjustment pattern in relation to role clarity $(\mathrm{C} 1: b=.20, p<.001 ; \mathrm{C} 2: b=-.00, p=.930 ; \mathrm{C} 3: b$ $=.19, p<.001)$, task mastery $(\mathrm{C} 1: b=.16, p<.001 ; \mathrm{C} 2: b=.00, p=.522 ; \mathrm{C} 3: b=.197, p<$ $.001)$, and feelings of acceptance $(\mathrm{C} 1: b=.17, p<.001 ; \mathrm{C} 2: b=.00, p=.64 ; \mathrm{C} 3: b=.19, p<$ $.001)$.

For Pattern C, newcomers with higher levels of a resource had higher early levels of adjustment (at 1 month) but subsequently adjusted at a slower rate than those who had lower levels of the resource; by 9 months, those with higher levels of the resource continued, however, to have higher levels of later adjustment. The personal resource of proactive personality showed this adjustment pattern in relation to task mastery $(\mathrm{C} 1: b=.44, p<.001 ; \mathrm{C} 2: b=-.02, p<.05$; $\mathrm{C} 3: b=.28, p<.001)$ and feelings of acceptance $(\mathrm{C} 1: b=.23, p<.001 ; \mathrm{C} 2: b=-.02, p<.05$; $\mathrm{C} 3: b=.11, p<.05)$.

For Pattern D, newcomers with higher levels of a resource had higher early levels of adjustment (at 1 month) and subsequently adjusted at a rate that was similar to those who had lower levels of the resource; however, by 9 months, those with higher levels of the resource had similar levels of later adjustment when compared to those with lower levels of the resource. The personal resource of organizational knowledge showed this adjustment pattern in relation to task mastery $(\mathrm{C} 1: b=.32, p<.001 ; \mathrm{C} 2: b=-.02, p=.21 ; \mathrm{C} 3: b=.18, p=.08)$, and the social resource of having met a manager on the first day showed this adjustment pattern in relation to feelings of acceptance $(\mathrm{C} 1: b=.10, p<.05 ; \mathrm{C} 2: b=-.01, p=.17 ; \mathrm{C} 3: b=.02, p=.74)$.

For Pattern E, newcomers with higher levels of a resource had similar early levels of adjustment (at 1 month) when compared to those with lower levels of the resource, and they subsequently adjusted at a slower rate than those who had lower levels of the resource; by 9 months, those with higher levels of the resource had similar levels of later adjustment when compared to those with lower levels of the resource. The material resource of having a work station ready on the first day showed this adjustment pattern in relation to feelings of acceptance $(\mathrm{C} 1: b=.03, p=.66 ; \mathrm{C} 2: b=-.02, p<.05 ; \mathrm{C} 3: b=-.13, p=.07)$.

For Pattern F, newcomers with higher levels of a resource had lower early levels of adjustment (at 1 month) and subsequently adjusted at a rate that was similar to those who had lower levels of the resource; however, by 9 months, those with higher levels of the resource had similar levels of later adjustment when compared to those with lower levels of the resource. The status resource of newcomer job level showed this adjustment pattern in relation to feelings of acceptance $(\mathrm{C} 1: b=-.03, p<.05 ; \mathrm{C} 2: b=.00, p=.89 ; \mathrm{C} 3: b=-.03, p=.07$. 
